\title{
Responsibility through Anticipation? The 'Future Talk' and the Quest for Plausibility in the Governance of Emerging Technologies
}

\author{
Sergio Urueña $(\mathbb{D}$
}

Received: 15 April 2020 / Accepted: 15 December 2021 / Published online: 8 January 2022

(C) The Author(s) 2022, corrected publication 2022

\begin{abstract}
In anticipatory governance (AG) and responsible innovation (RI), anticipation is a key theoretical and practical dimension for promoting a more responsible governance of new and emerging sciences and technologies. Yet, anticipation has been subjected to a range of criticisms, such that many now see it as unnecessary for AG and RI. According to Alfred Nordmann, practices engaging with 'the future', when performed under certain conditions, may reify the future, diminish our ability to see what is happening, and/or reproduce the illusion of control over the future. Several authors have stressed that these critiques fail to capture the heterogeneous character of anticipatory practices, and yet research on the question of what particular kind of socioepistemic engagements with 'the future' AG and RI aim to enact through anticipation remains fragmentary and their underlying rationale under-theorised. This article aims to advance the theoretical characterisation and problematisation of anticipation as key interventive tools for AG and RI. By distinguishing between four modes of anticipation and heuristically testing them against Nordmann's critiques, the article argues that despite his assessment failing to recognise the heterogeneity of anticipatory practices
\end{abstract}

S. Urueña $(\bowtie)$

University of the Basque Country UPV/EHU, Carlos

Santamaría D08, Plaza Elhuyar 2. 20018, San Sebastian,

Spain

e-mail: sergio.uruena@ehu.eus considered valuable for AG and RI, it reinforces the relevance of performing certain modes of anticipatory exercises, namely critical-hermeneutic ones. Thus, anticipation continues to be a necessary heuristic dimension for AG and RI. More concretely, the article maintains that such anticipatory heuristics may find their radical constructive and critical-reflective character in the dynamics of inclusive scrutiny and negotiation about the (im)plausibility and (un) desirability of the envisioned or (co-)created futures.

Keywords Anticipation · Plausibility · Epistemology · Technological governance ·

Responsible innovation

\section{Introduction}

The future has always been used in the responsibilisation of technological development. However, we have recently seen a growing call for responsibilising through anticipation. Different normative frameworks and interventive approaches-each with their own distinctive (though sometimes overlapping) rationales - recognise 'anticipation' as a useful interventive tool for promoting more responsible development of New and Emerging Sciences and Technologies (NESTs) from early stages of development, when epistemic and normative uncertainty and ignorance challenge their assessment and governance (e.g., [1-6]). 
Two umbrella frameworks that highlight the need for anticipation are anticipatory governance (AG) [7-9] and responsible innovation (RI) [10-13]. Through an inclusive engagement (in terms of knowledges and actors) with representations of 'the future', AG and RI aim to enable a range of capacities to the constellation of social actors that constitute the innovation co-production network, and thereby facilitate more self-reflexive and responsive ongoing research and development $(\mathrm{R} \& \mathrm{D})$ practices.

However, this incipient call for anticipation has not been accompanied by a specific and systematic conceptual development of this socio-epistemic practice within AG and RI literature. Presentations of 'anticipation' usually contain brief and nebulous characterisations, allusions to heterogenous existing methodologies/techniques, and brief mentions of their miscellaneous and general expected functional heuristics. For instance, anticipatory exercises are expected, among other things, to facilitate public engagement, increase resilience, foster critical appraisal of visions and promissory statements, or enhance understanding of the contingent and indeterminate innovation pathways and their associated potential impacts [7] (pp. 985-986), [13] (p. 31). What all these heterogeneous practices have in common, such that they are referred to as 'anticipatory', and what analytical prescriptions toward 'the future' anticipatory exercises require to enact all these heuristics are issues that remain only sketched and under-theorised [14] (p. 110).

Different prescriptions of what to do analytically with 'the future' can render different paradigms of responsibility $[15,16]$. In addition, intuitions about the concept of anticipation are in general poor (the mainstream way of approaching the future is as an arena awaiting to be epistemically conquered or strategically designed). In this light, it is crucial to move forward and elucidate the minimal features of anticipatory practices, the kind of socio-epistemic dynamics and heuristics that are possible to enact through these exercises, and which of these are desirable and worth pursuing (and how) for AG and RI.

This article aims to advance the theoretical characterisation and problematisation of anticipation as a legitimised heterogeneous interventive tool for AG and RI (i.e., for encouraging a more inclusive and responsive development of NESTs). For this purpose, I will consider Alfred Nordmann's assessments of the possible shortcomings of certain practices engaging with 'the future' as a valuable theoretical instrument for exploring potential virtues and limits of certain modes of anticipation. Because Nordmann's criticisms pose relevant questions for the very foundations and limits of anticipatory practices, a critical dialogue with his arguments can only help to assess the underlying legitimising rationale of anticipations.

Among other criticisms, Nordmann argues that practices engaging with 'the future' (i.e., the 'future talk'), when performed under certain conditions, may (i) reify certain future perspectives (e.g., propagating deterministic visions) [17], (ii) diminish our ability to see what is happening, and/or (iii) (re)produce the illusion of control over the future [18, 19]. While the first critique was specifically directed towards the anticipatory modus operandi of speculative ethics-it was never directed towards AG and/or RI as such-, the target of the latter two criticisms was anticipation as a tool for AG and RI. These last two criticisms served as premises for Nordmann to conclude that anticipation is not a necessary part of AG and RI [19] (p. 87).

While I agree with Nordmann on many points of his critiques - and even more so with his underlying concern about the dangers of misusing 'the future'-I do not support his conclusion. This is not to say that his arguments are invalid, but rather that his diagnosis of the value of anticipations for responsibilising the governance of innovation is constructed over a narrow concept of anticipation. His concept does not capture the socio-epistemic heterogeneity of these practices, and thus their functional diversity for AG and RI umbrella frameworks. In other words, I agree with Nordmann that anticipations, as he conceives of these practices-i.e., as 'a kind of preparedness that is based on knowledge of what may come in the future' [19] (p. 87)—can lead to the problems he identifies. However, the issue at stake is whether anticipation is (or should be) understood in that way within AG and RI.

In this respect, it is no coincidence that the brief and immediate reactions to Nordmann's critiques coming from AG and RI scholars were primarily focused on his expectations regarding anticipation. Specifically, the responses suggested that the heuristics they were seeking to achieve through foresight and anticipatory exercises were substantially different from those Nordmann assumed [2, 14, 20, 21]. However, these responses did not explicitly 
provide a basic conceptualisation and theoretical categorisation of 'modes of anticipation' and a discussion of the value of their respective possible accompanying heuristics for AG and RI, as is my intention here. ${ }^{1}$

Both Nordmann's narrow characterisation of anticipation and the lack of an explicit basic systematisation of what modes of anticipation exist point to an ongoing need to problematise how anticipation can (and/or should) be understood within AG and RI, and to adequately address the challenges arising from its theoretical characterisation and practical operationalisation. My argument is that it is precisely the deficiencies attributed by Nordmann to the 'future talk' (and his underlying worries about misuses of 'the future') that AG and RI seem intent on counteracting through the performance of certain types of anticipations. Therefore, his criticism, instead of showing that anticipation is unnecessary, reinforces the legitimacy of performing certain types of anticipatory exercises (while at the same time warning of the possible pitfalls of others). For instance, 'anticipation' and 'foresight' are broad enough to subsume exercises that Nordmann himself seems to consider valuablewithout conceiving of them as 'anticipations'-such as (non-speculative) 'thought experiments' [19] (p. 91) and 'vision assessment' [23].

The argument of the paper unfolds as follows. After this introductory section, I briefly contextualise the emergence of AG and RI discourses and outline different layers in which 'the future' becomes an important element for them ('NESTs 'Responsibilisation' and the Call for Anticipation: Anticipatory Governance and Responsible Innovation'). Next, I take some initial steps towards a more explicit conceptualisation of anticipation as an interventive tool and its socio-epistemic functionalities by distinguishing four

\footnotetext{
${ }^{1}$ For instance, Simone van der Burg stresses that instead of knowledge about the future, anticipation is used as a reflective, meaning-giving function to prevent decisions from being taken blindly [20, 22]. Marianne Boenink argues that anticipatory practices, such as socio-technical or techno-moral scenarios, do not aim to predict but rather emphasise contingency (although, as she stresses, to achieve this, they should be carefully executed) [2]. Cynthia Selin laments Nordmann's lack of background in Futures Studies when it comes to characterising anticipation (a discipline in which the various uses of the future are systematically investigated alongside interventive anticipatory methods with different rationales and goals) [21].
}

approaches to future representations, each of which renders a different general mode of anticipation. They are the predictivist, strategic, exploratory, and critical-hermeneutic approach ('On Four Approaches to 'The Future' and Four Corresponding Modes of Anticipation'). Then, I revisit Nordmann's three critical arguments against the 'future talk', examining to what extent each of these threatens the legitimacy of the modes of anticipation considered valuable for AG and RI. Concretely, I will show that despite Nordmann's assessments failing to recognise the heterogeneity of anticipatory practices considered valuable for AG and RI, a number of valuable lessons can be drawn from his criticisms. In particular, these criticisms help us to clarify why we need to focus on the constructive dynamics constituting anticipatory practices and to support critical-hermeneutic anticipations as a robust and key element in making discourses and practices that engage with 'the future' a legitimate part of 'responsibilisation' ('Staying with Anticipation? Nordmann's Criticisms of the 'Future Talk' for the Governance of NESTs'). I then note how many of the worthwhile critical-hermeneutic anticipatory heuristics for AG and RI practices would find their radical and critical-constructive character in the dynamics of inclusive scrutiny and negotiation about the plausibility and desirability of 'the futures' ('Responsibility through the Search for the Future's Plausibility and Desirability'). The paper ends with some concluding remarks ('Conclusions').

\section{NESTs 'Responsibilisation' and the Call for Anticipation: Anticipatory Governance and Responsible Innovation}

The use of future representations to support more responsible technological development has been a constant feature of technology assessment (TA) approaches since their inception [24-26]. However, our understanding of what is considered 'being responsible' in $\mathrm{R} \& \mathrm{D}$ contexts and the approaches towards temporality in the attempt to cultivate this responsibility have been (and continue to be) refined [27]. Nowadays, different discourses of responsibility co-exist, each with their own (sometimes overlapping) ways of engaging with the past, the present, and the future. 
For instance, TA's initial attempts in the mid1960s aimed to encourage responsible development of technologies on the basis of external and expertbased cost-benefit analysis supported by statements regarding the likely future ('hard') impacts of a technology (e.g., the US Office of Technology Assessment) [28]. TA aimed to provide policymakers with 'objective' and 'value-free' information of the future likely impacts of technological developments, thus only indirectly intervening in decision-making processes. However, early on, this expertocratic, positivist, and predictivist conception of TA was called into question in response to a range of historical and intellectual changes and societal challenges [29]. On the one hand, the restriction of the assessment activity to experts was soon challenged when new forms of TA (e.g., participatory TA) stressed the need to involve stakeholders or citizens and consider their different perspectives and values. On the other hand, the Collingridge dilemma (1980)—which is widely mentioned and often wrongly conceived as a problem to be overcome [30]—stressed our epistemic precariousness when trying to influence technological change (given the recognition of its indeterminate and nonlineal character): It is precisely at the stage of development when we are most likely to influence R\&D in order to avoid technology's uncritical entrenchment, or lock-in [31], that uncertainty and ignorance obstruct the possibility of illuminating the possible consequences and action horizons that might arise from them [32].

Recognition of this epistemically precarious state, together with the more nuanced and complex understandings of the messy and multidimensional constellation of processes constituting the de facto governance arrangements of science and technology presented by Science and Technology Studies (STS) — broadly understood-[33-37], did not relieve subsequent TA approaches of their impetus to promote responsible development of NESTs from early stages through representations of the future (i.e., through anticipatory practices).

A clear example is constructive TA (CTA). CTA emerged in the mid-1980s (e.g., the Netherlands Organisation of Technology Assessment) as a 'new design practice' [38] (p. 255) built on a 'coevolutionary' conception of science-society relationships. Although CTA shifted the focus away from 'likely future impacts', it adopted 'anticipation' as an instrumental tool for participatively and proactively enhancing reflexivity within the design, development and implementation processes [26]. In this vein, CTA proposed to build 'TA activities into the actual construction of technology', during the ongoing 'coevolution' between science and society [38] (p. 252). Socio-technical scenarios are interventive anticipatory exercises considered favourably by CTA to promote social learning and reflexivity [39] and explore 'endogenous futures' [40].

Another noteworthy aspect of CTA is that it not only incorporated anticipation as a non-predictivist interventive tool, but also considered anticipatory dynamics (e.g., expectations, visions, future imaginaries) as a constitutive guiding force in science and technology co-production processes: 'Co-production processes include anticipation. Technical change is driven partly by the historical experience of actors, their views of the future, and their perception of the promise or threat of impacts which will change over time' [38] (p. 257). Early contributions in STS and the sociology of expectations helped to formulate and reinforce this diagnosis [41-44], and fuelled the need to amplify the repertoire of TA methods engaging with futures by including, for instance, vision assessment [23, 45, 46]. Thus, CTA already reflected the two interrelated dimensions under which anticipatory phenomena are understood today, i.e., as interventive tools and as anthropological and sociological phenomena that, among many other influences, shape our actions [47, 48].

In critical dialogue (and quite a lot of overlap) with CTA, David H. Guston and Daniel Sarewitz [3] proposed in the early 2000s to develop real-time TA (RTTA). The main innovation of RTTA in relation to CTA-beyond some differences in their interventive techniques and operative methods, see [3] (pp. 100-106) - is that RTTA ambitiously and radically proposes to embed TA within the knowledge coproduction processes themselves. More concretely, it aims to build up actors' capacities for action 'on synchronous reflection and adjustment' [3] (p. 100) by integrating socio-technical mapping and dialogue with retrospective (analogies) and prospective (foresight) analysis. RTTA aims to integrate scientifictechnical research with social sciences and humanities from the outset, thus making inherent to $R \& D$ practices the project that emerged in the 1990s of 
addressing their ethical, legal and social implications/ aspects (ELSI/ELSA) [49].

The previously depicted-inevitably inexhaustive and simplified - trajectory of TA may serve to illustrate the radicalisation that had arguably taken place regarding what it is 'to be responsible' within the normative and interventive frameworks of science, technology and innovation. This radicalisation refers to at least three issues: (i) which aspects of R\&D are the subject of analysis (e.g., from the impacts of technologies to the whole innovation process); (ii) which agents come into play when assessing and responsibilising R\&D (from experts to distributed co-production and responsibilisation); and (iii) the position of TA with respect to the R\&D enterprises (from a TA isolated from $\mathrm{R} \& \mathrm{D}$, or a TA whose experiments feed into $\mathrm{R} \& \mathrm{D}$, to a TA that aims to be systematically integrated from within the constellation of co-production processes themselves). In all these processes and discourses, the engagement with 'the future' is in one way or another understood as an instrument of great heuristic value for orienting actions. TA approaches currently recognise anticipation as a key operational dimension for enhancing reflexivity [4]: 'the future' is used as both a multidirectional tool [50] and an object of investigation [51].

Anticipatory governance (AG, 2008-) and responsible innovation (RI, 2011-) can be situated within this general trajectory of broadening the responsibilisation of $\mathrm{R} \& \mathrm{D}$ governance while maintaining this future-oriented character. Both frameworks are rooted in previous TA approaches ${ }^{2}$ and in other STSrelated interdisciplinary fields concerned with public engagement and the increase in legitimacy of worldmaking processes (e.g., environmental studies, science policy). Moreover, they both emerged in response to diverse institutional needs ${ }^{3}$ and academic and policy

\footnotetext{
2 While the influences of RTTA and other approaches on AG are clear given the involvement of David H. Guston in the conception of both approaches [7-9], in the case of RI the influence of CTA, RTTA, and AG is explicitly recognised [10] (pp. 751-754), [13] (p. 28).

3 The emergence of nanotechnology was fraught with uncertainties and institutional concerns about its public perception and acceptance. Considering earlier impasses with other NESTs (e.g., genomics), the demand for inclusive and responsible governance by institutions from the USA and Europe was instrumentally increased. As Arie Rip notes, 'nanophobia-phobia' could be found in many discourses [52] (p. 350).
}

opportunities. For instance, the Center for Nanotechnology and Society (Arizona State University, USA), whose strategic guiding vision was to foster the AG of nanotechnologies, was funded by the National Science Foundation 'to facilitate nanotechnology funding policies in the US' [53] (p. 1094). At the same time, it embodied the conviction within the STS community that the emergence of nanotechnology provided an opportunity to 'test' the scope and limits of promoting a more inclusive or democratic governance of a NEST from the outset [9].

AG and RI are considered 'umbrella frameworks' precisely because they attempt to ambitiously embrace and systematise a great diversity of existing approaches and techniques [54] (pp. 16-17). They also strive to respond to a number of evolving challenges identified in various academic and institutional domains with regard to innovation governance. Arguably, AG and RI intend to respond comprehensively to the following interrelated challenges - all of which contain a direct or indirect appeal to the future, and many of which overlap with those previously recognised by TA approaches, see [29] (p. 1103):

1. Early and extended social intervention: In order to avoid uncritical socio-technical entrenchment, early social intervention throughout the whole $R \& D$ process is recommended. The early intervention has to be "well-timed so that they are early enough to be constructive but late enough to be meaningful' [12] (p. 1571). It conveys that future-making practices performed in the present should not be discounted or left to chance, but rather collectively problematised and its possible alternatives kept open in order to facilitate the modulation of technology (i.e., this is required for addressing the Collingridge dilemma [55]).

2. Performativity of promises and hype on NESTs: The not-yet-existing temporal character of NESTs situates them in a space that is deeply anchored in promises and imagined (speculative) futures [56, 57]. $A G$ and RI-following vision assessment approaches [58] - propose to critically engage with existing promises, expectations, imaginaries and visions to prevent them from blindly and illegitimately influencing decision-making and the purposes, motivations and ends of innovation (e.g., by shaping the agenda and allocation of recourses). 'The future' refers here to all those 
representations and discourses of the future that overwhelm the present and narrow the space for alternative actions (e.g., by creating a form of tunnel vision).

3. Socially-robust risk research: This alludes to the challenge of conducting risk assessment processes in a comprehensive manner. This comprehensiveness concerns both the contents (i.e., the consideration of 'hard' and 'soft' [59] as well as 'positive' and 'negative' [60] impacts and aspects) and the procedures (the treatment of those impacts and aspects in relation to normative concerns such as the purposes or motivations of research). This requires socio-technical integration in R\&D processes. 'The future' appeals to the different ways in which innovation could influence how socio-technical and techno-moral systems co-evolve.

4. Political radicalisation and upstream public engagement: The goal here is to address all previous challenges through inclusive deliberation processes in order to align $\mathrm{R} \& \mathrm{D}$ early motivations, processes and outcomes with the interests and values of societal actors. Here, 'the future' is understood as an arena pregnant with possibilities and projects of socio-political nature.

In addressing these challenges, both frameworks propose a series of elements or dimensions that function as procedural norms. Innovation processes or systems are considered more or less responsible depending on the degree to which they continually unfold by meeting these procedural norms. These elements or dimensions must be understood in an integrated or assembled way. Although all of these dimensions are necessary, none of them alone is sufficient; they all are co-dependent and they mutually reinforce each other (see Table 1).

The previous four dimensions/elements co-configure a guiding principle for action. Echoing previous proposals (e.g., [62]), AG and RI endorse a concept of responsibility that is considered 'future-oriented' and normatively procedural in character (i.e., it is not based on substantive norms or values). The substantive values are expected to emerge from the very processes of ongoing inclusive experimentation and deliberation (in a bottom-up mode). Based on the constructivist consideration that innovation is a world-making force [63], and that it shapes present and future possibilities, the idea of AG and RI is to

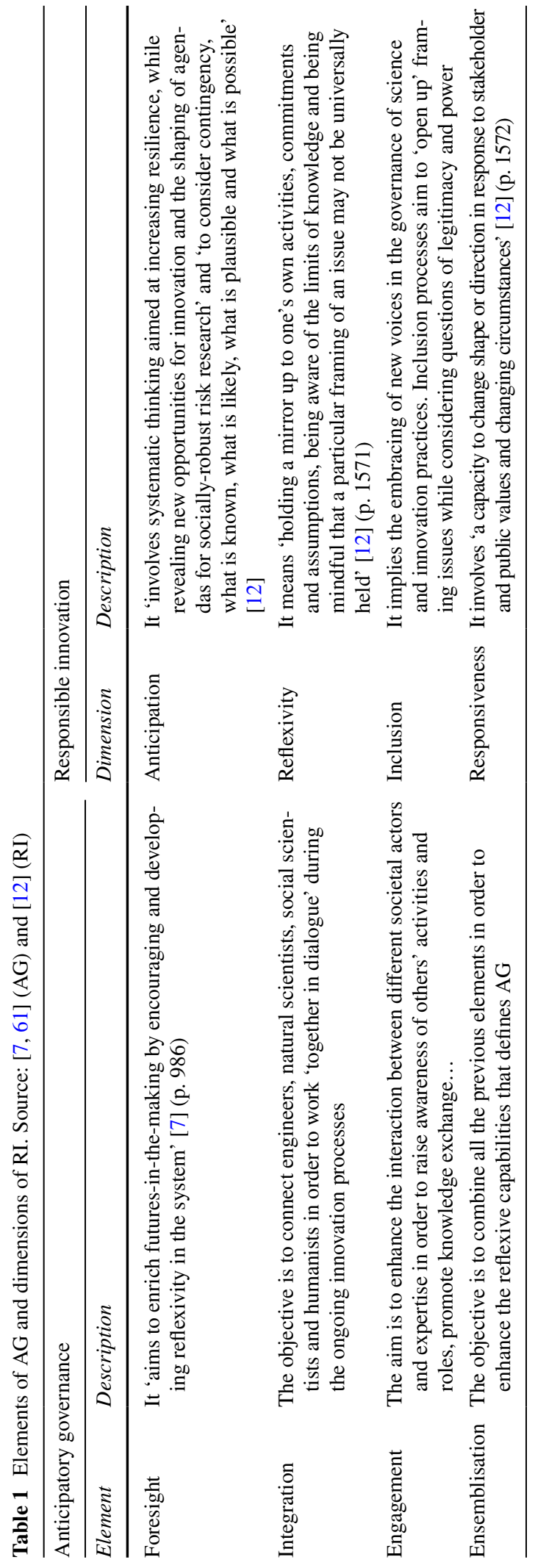


proactively and collectively assume 'the threads of innovation' (within our significantly restricted capacities and considering our available resources). For instance, RI is explicitly defined as 'taking care of the future through collective stewardship of science and innovation in the present' [12] (p. 1570).

Therefore, the future is involved in AG and RI both in the challenges they seek to address and in their underlying concept of responsibility (through the anticipatory element). However, that concept of responsibility is recognised as being somewhat general, and vague, and 'unresolved in terms of its political, institutional and normative imaginaries and practices' [13] (p. 27). This vagueness and unresolved character affect (and simultaneously are affected by faintly detailed characterisations of) anticipation: What kind of procedural socio-epistemic mechanisms are (not) considered when characterising anticipation in the foundational texts of these frameworks? What engagements with 'the future' do they seem to promote? The following section provides a more detailed (though still preliminary) answer to these questions, distinguishing between four general modes of anticipation considered (un)favourable for AG and RI.

\section{On Four Approaches to 'The Future' and Four Corresponding Modes of Anticipation}

The founding texts of AG and RI contain both negative and positive characterisations of 'anticipation' and 'foresight'. These characterisations are usually brief and place particular emphasis on the methods/ techniques by which the anticipatory dimension could be operationalised and/or the heuristics intended to be achieved. These considered methods and heuristics are heterogeneous and, in some cases, have little in common (each embracing distinct rationales and prescriptions on how to approach and what to do with 'the future').

In this section, and after offering a basic concept of anticipation ('Engaging with 'Futures': Basic Socio-epistemic Steps in the Performance of Interventive Anticipations'), I will distinguish-without claiming any exhaustiveness or supposing typological rigidity-four distinct analytical approaches to 'the future', and four corresponding modes of anticipation that are implicitly considered (un)favourable within AG and RI's foundational texts. These are the predictivist ('Anticipation and Robust Epistemic Models of the Future: the Predictivist Approach'), strategic ('Anticipation and Future(s)-planning: the Strategic Approach'), exploratory ('Anticipation and Opening up the Alternative Future(s): the Exploratory Approach'), and critical-hermeneutic ('Anticipation and the Analysis of the (Production of) Existing Representations About the Future: the Critical-Hermeneutic Approach').

The purpose of this elucidation is twofold: On the one hand, I attempt to move towards a more explicit characterisation of interventive anticipations. On the other hand, I want to emphasise that anticipatory practices are heterogeneous in nature. Recognition of this heterogeneity ought to be a starting point when assessing the virtues and/or limitations of interventive anticipatory practices in support of AG and RI.

Engaging with 'Futures': Basic Socio-epistemic Steps in the Performance of Interventive Anticipations

'Anticipation' is considered within Futures and Anticipation Studies as an activity characterised by the use of a future representation (or a future scenario, from now on ' $F S$ ') (consciously or not) in order to guide actions in the present $[64,65]$. Anticipatory exercises are typically characterised as consisting of 'two elements: a model and its translation into action' [64] (p. 14).

Anticipation co-exists as both a sociological and/ or anthropological de facto phenomenon (e.g., countless of our individual and social actions are based on visions, expectations, and other images of the future) and a tool for intervention (e.g., forecast and foresight practices) [47]. Through foresight and anticipation, AG and RI-as well as other STS scholars-aim to intentionally intervene and mobilise (e.g., study, criticise, enrich, complexify) the constellation of FSs at stake that constitute the de facto anticipatory dynamics of innovation.

The more than 35 methods currently existing within Futures Studies [66] illustrate that the 'uses' of FSs are manifold. The different possible epistemic, normative, and/or ontological approaches to $F S s$, as well as the different processes and ends that could be pursued through their use, could constitute different modes of interventive anticipation and produce different kind of anticipatory heuristics. These heuristics, 
Fig. 1 Basic steps of anticipatory actions



in turn, can be functional in certain application contexts, but not in others.

The multifaceted nature of anticipation highlights the need to further elaborate the previous minimum definition based on 'two elements'. Arguably, anticipatory practices require the execution of at least the following four basic socio-epistemic steps (Fig. 1):

1. Construction of FS: In order to 'use' an $F S$, it must first be created (regardless of whether the FS is produced by the same agents that will translate it into action). The process of constructing $F S s$ is influenced by a wide range of interrelated factors (e.g., the (quality of the) information considered, the methodology employed, the future timeframe chosen, the objective(s) pursued, the actors involved).

2. Interaction (approach and engagement) with FS: The engagement with $F S$ can be undertaken from several perspectives and adopt different modalities. The different possible affective, moral, and/or epistemic dispositions that might govern the interaction with FS configure different modalities of anticipation (each of which could have its specific role within specific $R \& D$ phases, areas, and dynamics). For example, the FSs produced through scientific forecasting methods are typically approached as robust representations of what is likely to be the case, while the FSs produced by science-fiction writers tend to be interpreted as socio-cultural expressions.

3. Extraction of information/heuristics from $\mathrm{FS}$ : The interaction with $F S$ enables the subsequent 'extraction' of information/heuristics considered relevant for guiding or directing action in the present.

4. Translation of information/heuristics into action: Once information has been extracted, it is interpreted and translated into action (with more or less strength and success).

These four basic steps are interrelated in a complex and iterative way (e.g., the operationalisation context and the goal(s) pursued may ex ante constrain how FSs should be constructed, approached, and what information counts for illuminating action). Adequate coordination between all the steps is considered a necessary (but not sufficient) condition for effective interventive anticipatory practices.

In the following sub-sections, I will distinguish four general approaches to FSs that constitute different co-existing modes of performing anticipation: the predictivist, strategic, exploratory, and critical-hermeneutic. In doing so, I do not intend to be exhaustive. Indeed, there might be different overlaps and combinations of the identified modes of anticipation. To extend, develop, and refine this classification by considering these possible combinations and other important variables (e.g., actors involved, timeframes, purposes, iterative processes, and feedbacks would exceed the limits of this paper.

The four approaches could be placed on a gradual scale, ranging from those 'representational and projective', where the focus on FSs lies in their projective or representational force (i.e., in the causal chains or images of the future they depict), to those 'meta-representational and reflective', where the focus on FSs lies in their underlying socio-political, ethical, and epistemic assumptions and/or its (co-)production processes. In this sense, 'meta-representational' approaches to FSs introduce a second-order reflexivity into 'representational and projective' anticipatory practices [67] (see Table 2). 


\section{Anticipation and Robust Epistemic Models of the Future: the Predictivist Approach}

The customary way of understanding anticipation is as an activity consisting of providing orientation on the basis of prospects of the future (i.e., on the basis of an $F S$ constructed and approached as a forecast or prognosis) [steps 1 and 2]. The information represented in FS is then analysed [step 3] and translated into action in order to either minimise, avoid, or accelerate/optimise the occurrence of the forecasted impacts [step 4].

A common example of this mode of anticipatory action would be to pick up an umbrella after seeing in the weather forecast that it will most likely rain. ${ }^{4}$ In the context of NESTs assessment, the predictive FSs are expected to provide accurate knowledge regarding the probable impacts that a technology could produce if implemented. This anticipatory modus operandi prevails in mainstream risk assessment practices and, as briefly mentioned in 'NESTs 'Responsibilisation' and the Call for Anticipation: Anticipatory Governance and Responsible Innovation', it was considered functional within classic TA approaches. FSs are used here as input information to support subsequent costbenefit analysis and create precautionary, adaptive, or mitigation strategies.

Despite the well-known benefits of forecast models for optimising decision-making, there are nevertheless some weaknesses when they are broadly applied for comprehensively governing innovation [68] (p. 238). On the one hand, there are concerns about the epistemic feasibility of forecasting. Forecasting and predictivist approaches require uncertainty to be managed and minimised as much as possible (instead of acknowledging it as a constitutive feature of the target systems) [69]. The management

\footnotetext{
4 Any predictive anticipation has to be combined with a strategic anticipatory practice and normative statements to meaningfully transfer the information extracted from the $F S$ model into practice. To act in the way depicted by the example would require one to assume the normative stance that 'a future in which one gets wet from the rain is not desirable and should therefore be avoided'. This simple and trivial example shows the possible co-existence and complementarity that exist between different modes of anticipation. The sequence in which the modes of anticipation are integrated in practice makes a big difference to the heuristic outcome of the exercises.
}

of uncertainties regarding the development and coevolution of NESTs is frequently limited or impossible (e.g., the case of nanotechnology), and predictive practices usually cannot deliver their expected outcomes. This is especially the case when the focus shifts from the 'hard' to the so-called 'soft' impacts [59] and more holistic issues are included in the equation (e.g., the relationship between humanity and technology, the distribution of positive impacts), as these are hard or impossible to predict $[62,70]$.

On the other hand, grounding the interventive governance of innovation on predictivist anticipations is politically problematic. For instance, these exercises on their own do not directly address the relative openness of the future and the socio-political constructive dimension of socio-technical systems, often reproducing linear or deterministic conceptions of $R \& D$ development. Decision-making practices based solely on scientific-technical prognosis often fail to recognise that innovation and technological development are a socio-political matter of concern and not just a technical matter of fact [71]. Moreover, the forecasted FSs that serve as the anticipatory substrate of anticipatory predictivist actions are formulated on the basis of assumptions about the maintenance of certain socio-political trends and structures (ceteris paribus clauses) that are not explicitly the object of critical scrutiny when projecting the future and illuminating action. If predictions are not critically considered, they could subtly function as safeguards of the status quo [72, 73] (pp. 23-35).

These and other limitations make it difficult for predictive anticipations to be regarded as legitimate or favourable instruments for AG and RI. In fact, AG and RI scholars explicitly exclude this mode of interventive anticipations as tools for responsibilisation: 'Forecasting can be set apart (...) in its orientation toward accurate predictions and allegiance to technological determinism' [7] (p. 985). 'Anticipation is here distinguished from prediction in its explicit recognition of the complexities and uncertainties of science and society's co-evolution' [12] (p. 1571)see also [9] (pp. 223 and 225-226). 'An anticipatory disposition is not about seeing into the future (prudence) or saying what the future is going to be (prediction) or estimating the chances of a certain outcome (probabilistic forecasting)' [61] (emphasis added). 


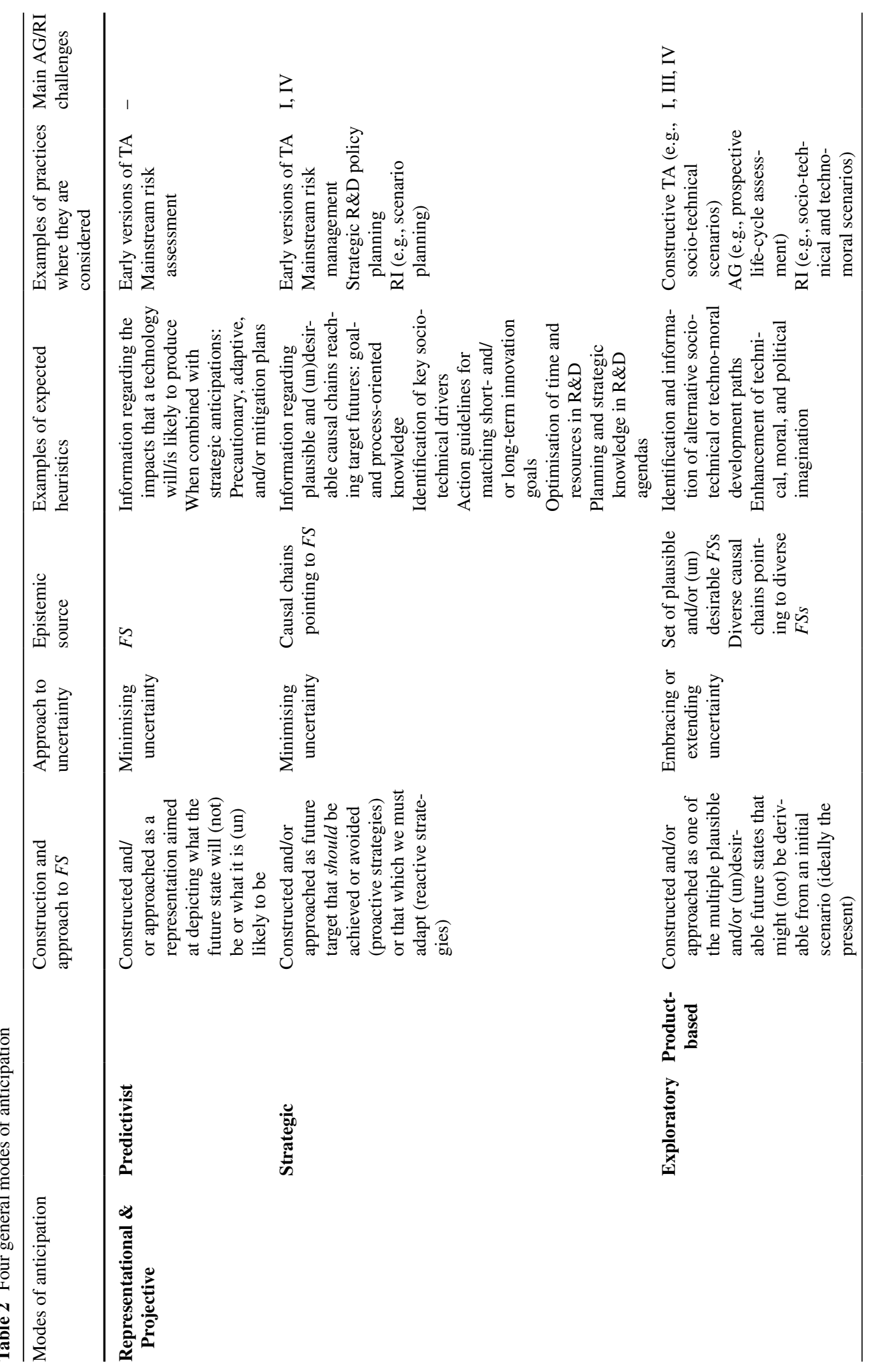




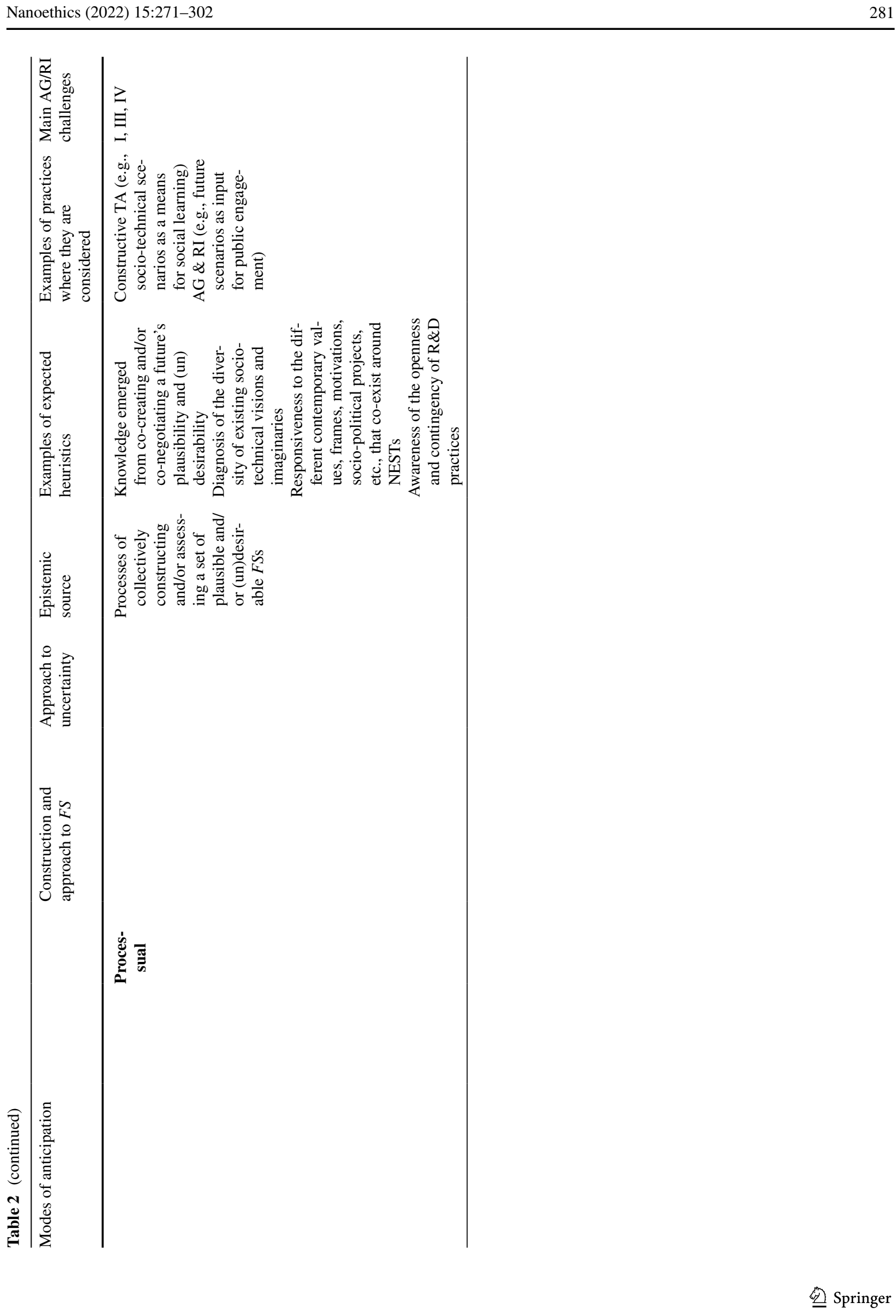




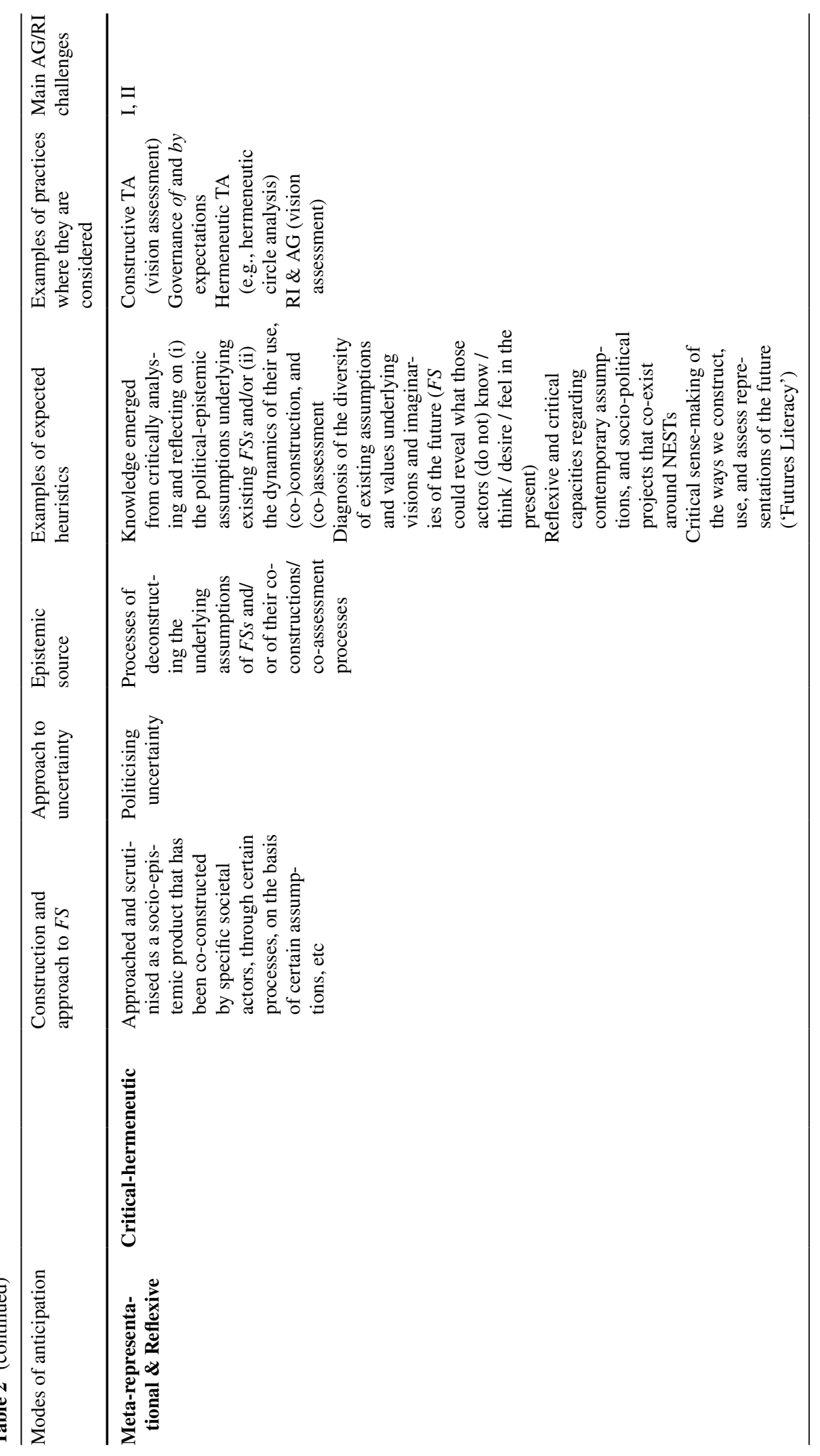


Anticipation and Future(s)-planning: The Strategic Approach

Another mode of anticipation is strategic in character. It requires constructing and/or approaching an $F S$ be it created through a reflexive process or uncritically taken as given-as a future target of intended realisation or avoidance [steps 1 and 2]. The heuristics of interventive strategic anticipatory practices (e.g., scenario planning, corporate foresight) do not lie entirely in the $F S$ considered, but rather in the causal chains, 'driver forces' or roadmaps projected to point to $F S$ from the present. Establishing these causal chains requires typically minimising uncertainty on the basis of knowledge about past and present trends and assumptions about continuities and novelties in the future [step 3]. The considered 'branching points' related to 'issues' or 'events' that might be disruptive are subsequently used to (re)configure the standing strategies or goals in order to avoiding risks, increase the resilience, and/or optimise our present actions towards/against the (partial or total) potential materialisation of an $F S$. The derived strategies are often described as 'future-proof' because they are thought to be a vaccine against possible future drawbacks that could undermine the achievement of the pre-established FS [step 4].

This mode of anticipation has been systematically enacted through methods such as scenario planning and strategic/corporate foresight (e.g., backcasting scenarios, relevance trees, or roadmapping exercises) by industrial and governmental actors since the 1950s [74] (e.g., the Shell scenarios in the late 1960s and early 1970s [75, 76]). In R\&D, interventive strategic anticipations are widely used for designing and assessing R\&D policies and/or research agendas (e.g., [77, 78]); i.e., for creating both technology 'pull' and 'push' innovation strategies towards pre-settled desired target futures [79] (p. 186) (see, for example, regarding nanotechnology $[80,81])$. These anticipatory practices have a clear normative force that lies in their capacity to fix the 'future paths' and objectives towards which present R\&D actions should (not) be oriented.

While the question of what future ends are considered (un)desirable to pursue through $\mathrm{R} \& \mathrm{D}$ processes and how these should be pursued seems central to AG and RI, the ways in which strategic anticipations could be included within these frameworks is not free of tensions. To a large extent, such tensions emerge as a result of a contrast between three aspects: (i) the closure of the future caused by the fixation of the FS target and the pathways that may lead to its achievement/evasion, and the dynamics of opening-up future alternatives that $\mathrm{AG}$ and $\mathrm{RI}$ seem to encourage regarding both the discussion of future goals to be pursued and the ways to achieve them; (ii) the minimisation of uncertainty required to identify potential pathways and obstacles to achieving $F S$, and the call for AG and RI to embrace intrinsic uncertainties; and (iii) the illusion of determinism or control that strategic anticipatory practices might (re)produce, and the contingent, messy and unruly conception of sociotechnical co-evolution that AG and RI endorse-in line with current STS advances.

Perhaps it is these tensions that prompted AG and RI architects to warn of some of the inadequacies of this kind of anticipation for enhancing responsibility. For example, Barben et al. argue that forecasting methods 'figure prominently in roadmapping exercises' [7] (p. 986) in their need to limit uncertainty. Strategic anticipation exercises could therefore be affected by the limitations described in the previous subsection. Similarly, while Stilgoe, Owen and Macnaghten include scenario planning as a valuable tool for responsibilising innovation, they also warn against the dangers that such techniques (and other anticipatory ones) may entail: 'used narrowly they risk exacerbating technological determinism' [12] (p. 1571). Consequently, assessing whether strategic anticipatory practices are an appropriate tool for promoting AG or RI might require us to examine both how the $F S$ considered was fixed and which assumptions and cognitive predispositions towards the future were established in the 'roadmapping exercise'. This would require a consideration of the concrete socioepistemic dynamics through which these practices are constructed.

Anticipation and Opening Up the Alternative future(s): the Exploratory Approach

This third mode of anticipation entails the construction and engagement with several FSs that have been co-constructed (and that are approached) with diminished epistemic and strategic ambitions: as representations that explore a more or less extensive area of 
alternative plausible and/or desirable futures that might be derivable from a given system.

Perspectives that seek to overcome the predictivist paradigm tend to emphasise that the future is ontologically open and deeply indeterminate. Rather than being based on representations of what is likely to happen, anticipations here are primarily based on multiple exploratory socio-technical or techno-moral alternative future paths, which, while plausible and/ or desirable to some, could not seriously be contemplated using traditional forecasting methods. By collectively exploring and projecting alternative and imaginatively controlled future possibilities, $F S s$ aim to establish the range of 'the plausible' and 'the desirable' considering different societal actors' knowledge, preferences, and values. Anticipation functions here as an exploratory tool to engage with the constructive and normative facets of R\&D.

Exploratory anticipations do not seek to minimise uncertainty about what will or is likely to happen; rather, they aim to recognise and embrace such uncertainty. In contrast to predictive and strategic anticipations, the success of exploratory practices is independent of the realisation of any FSs. Rather, their success depends on obtaining heuristics that reflexively enrich the decision-making processes in the present. As such, their objective is not to provide knowledge of the future, but to open up the plurality of plausible and desirable paths that could be considered within present socio-technical co-construction processes. The aim is to learn through anticipation [steps 1 and 2].

The heuristics of these exploratory exercises can arise (or be extracted) from both (a) the products of projective practices (i.e., from the co-created $F S s$ ) and/or (b) the very process of co-creating FSs with this exploratory spirit.

On the one hand, (a) in exploratory product-centred anticipations, the FSs-alternative socio-technical [40] or techno-moral scenarios [5, 82]—might illuminate diverse potential socio-technical and/or techno-moral (re)configurations that might co-evolve from a NEST development (e.g., discovering potential risks, positive outcomes, uses, opportunities, drawbacks). This includes both potential 'hard' (e.g., environmental and health risks) and/or 'soft' impacts (e.g., power and social relations, understandings, culture, values, morality) (see [22, 83]). Moreover, when exploration is performed by including a normative perspective, FSs can illuminate the various options for action that are currently open (e.g., broadening and problematising the variety of future objectives that could be considered for the orientation of actions when performing strategic anticipations).

As far as FSs here are an illuminating tool for current practice, it is expected that this exploration, while leaving enough room for imagination, will somehow be 'informed' or 'educated' [22] (p. 143) and, thus, 'be the product of a controlled reflection' [83] (p. 99). This aspiration towards epistemic and normative robustness is expressed in the pursuit (and assessment) of the scenarios' plausibility and desirability. This includes, as a matter of principle, information appealing to the past (e.g., possible analogies with past technologies), the present (e.g., a diagnosis of current situations and available knowledge), and the future (e.g., informed assumptions about what might be the case in the future) [step 3(a)].

On the other hand, (b) the anticipatory heuristics that may emerge from processual (or process-oriented) exploratory anticipations are principally aimed at increasing awareness of the (relative) openness and contingency of future-making and enhancing reflexivity in respect of the roles and visions that the different societal actors may have about the NESTs at issue. The processes of co-creating and/or co-engaging with FSs are based on assumptions that normally remain tacit. When the explorations are accomplished through collective and deliberative processes-i.e., including different societal actors (presumably with different framings, knowledge, values, feelings) - the different set of values and assumptions involved may lead to the projection of different $F S s$, some of which may be compatible, while others might be incompatible or even incommensurable. The plurality of values and viewpoints that may arise during exploratory anticipatory practices may depict not only the different visions, expectations, assumptions and frames of thought that co-exist around the NEST at hand, but also the diversity of socio-political projects (or pragmatic paths of action) that may be worth debating and pursuing/avoiding in the present. As such, they present the diverse "endogenous futures" that might be in-the-making [40].

Here, the set of $F S$ s are regarded as a medium (i.e., they are considered to be of relative limited importance). The important elements are the communicative processes themselves and the arrangements 
and capabilities that are developed from these (e.g., [84]). 'Processual foresight' and 'anticipation' could be conceived as interventive socio-epistemic instruments aimed at creating a space for social learning and capability-building $[26,85] .^{5}$

These processual exploratory practices are conceived as exercises for enhancing public engagement and disrupting frames of thought, broadening moral and ethical imagination, creating awareness of the contingency and complexities of future-making practices (the future can be-and probably will be-'otherwise' [88]), and reflecting on our roles in current futuremaking patterns. Through projecting and deliberating on plausible and desirable futures, these activities use the set of FSs with the aim of promoting reflexivity regarding the different modes through which we represent, think, feel, and use 'the future' while acting in the present. Explorative foresight processes aim to provide heuristics for more socio-politically robust (inclusive, responsive, and reflective) ways of world-making [89] [step 3(b)].

Although the activity of collectively conceiving and/or engaging a plurality of scenarios does not offer a concrete orientation per se [90], the resulting heuristics are expected to enrich subsequent anticipatory decision-making processes both regarding the FSs' content (e.g., broadening considered future impacts/aspects of NESTs and alternatives for R\&D, enhancing context awareness) and in the way they are constructed and approached (e.g., recognising uncertainties and contingency, overcoming linear and deterministic thinking about technology-society coevolutionary paths) [91] (p. 725) [step 4].

\footnotetext{
5 The potential learning impacts of foresight - although often poorly monitored and assessed-are claimed to be manifold [86]. Boenink describes how some anticipatory practices, such as socio-technical and techno-moral scenarios, are "not much about content, but about training specific capacities and skills of users' [2] (p. 155). More concretely, she claims that 'they offer material to train what the Greeks called phronesis: practical wisdom. This is the capacity to judge concrete situations: to interpret the situation and assess what would be the best thing to do in this case' [2] (p. 155). The use of foresight techniques by AG and RI (and other STS) scholars can be read as an example of what counts as 'relevant social science' for Bent Flyvbjerg. This is not an attempt to pursue a social science along the lines of the natural sciences (i.e., with an emphasis on episteme and techné), but rather an attempt to promote socially relevant and practical wisdom (i.e., phrónesis); a knowledge that is relational, practical, contextual or situated, value-based and sensitive to power relations [87].
}

Having its origins in Futures Studies, foresight exploratory practices (both process-centred and processual) have been widely used in multiple disciplines. Already present in CTA [26, 40], in AG and RI exploratory foresight exercises are considered an input for public engagement and a means to strengthen moral imagination and risk assessment processes (e.g., [85, 91-93]).

Exploratory anticipations can integrate within their dynamics the next approach to FSs that constitutes another mode of anticipation: the critical-hermeneutic. Although the process of exploring alternative futures tacitly involves identifying different visions, expectations, assumptions, and values [94] (pp. 103-104) which in turn could help to open up or enrich the FSs that are being considered for the orientation of action-the levels of reflection inherent in these processes (and thus the reproduction or implicitness of certain assumptions rather than others) can assume different degrees of transparency and depth. If a more explicit and radical reflexivity is desired, a further step must be taken: to approach these $F S s$ from a criticalhermeneutic perspective.

Anticipation and the Analysis of the (Production of) Existing Representations About the Future: the Critical-Hermeneutic Approach

The fourth mode of anticipation aims at approaching the FSs (and their respective construction dynamics) that serve as substrates for both formal (e.g., predictive, strategic, and exploratory practices) and informal (e.g., imaginaries, visions, and expectations) anticipatory activities as objects of critical scrutiny, reflection, and responsibility.

This type of critical approach has been present in Critical Futures Studies since the early stages of the 'discipline' [95], although the most systematic criticalhermeneutic theoretical and practical contributions began the late 1980s and early 1990s (e.g., [96-98]). Similarly, the study of the performativity of the future in STS began to gain momentum in the second half of the 1990s [43, 44], and in the 2000s interventive critical-hermeneutic approaches and methods such as vision assessment began to emerge as a response [23, 45, 99] and opened up the way to actual hermeneutic analysis of NESTs [100].

The starting point for understanding the rationale of this mode of interventive anticipations is the 
recognition that diverse $F S s$ de facto co-exist in our societies [101] (p. 1) and configure anticipatory discourses, ways of feeling and knowing, and power relations. For instance, STS scholars have shown how (often highly speculative) socio-technical imaginaries [57], expectations [102], and visions [103, 104] play a strategic and meaning-giving role when supporting the socio-political and technical relevance of certain NESTs (to the detriment of others) [41, 47]. Anticipatory discourses modulate public perception about NESTs and innovation practices (e.g., reproducing deterministic and linear visions of $R \& D$ ), shape the creation of socio-political assemblages, and mobilise and direct human attention and material resources towards specific goals (to the detriment of others) [94]—thus influencing what knowledge could be developed in the future [70]. Because these anticipatory discourses might be considered as political and socio-epistemic anticipatory artefacts operating within the de facto and tentative governance of science and technology [53, 105] (pp. 75-96), they are recognised as objects of responsibilisation [58, 104, 106] and governance [47, 94, 107] [step 1].

Through a critical-hermeneutic engagement with these discourses, the aim is to promote 'their deconstruction and hermeneutic reconstruction' [23] (p. 93). This entails identifying, understanding, and criticising the underlying epistemic and normative assumptions and the embedded meanings of FSs $[20,108]$. From a more process-centred perspective, a critical-hermeneutic approach could also include the analysis of the FSs' construction processes, the dynamics of assigning meaning to them, and the monitorisation of their impact on society [58]. Some of the key questions are ${ }^{6}$ : What meanings are attributed to FSs? Which actors promote these FSs and meanings, and why? What interests and power dynamics do FSs reflect and reproduce? Who is represented in these FSs? Thus, by interacting with existing FSs, the aim is not to minimise or embrace uncertainty, but rather to politicise it [step 2].

As Armin Grunwald argues, these activities can provide relevant information for the responsible development of NESTs. Above all, the analysis provides a diagnosis of our present [58]: epistemic and normative assumptions can provide information about

\footnotetext{
${ }^{6}$ For a more complete list of questions and issues addressed by TA approaches, see [58] .
}

the expectations, interests, and beliefs that different social actors have about a NEST. The identification of assumptions and their contextualisation also facilitates the assessment of their plausibility, feasibility, and desirability, eliminating speculative excesses as far as possible [109]. The speculative bubbles that have surrounded many NESTs, and the ability of these to shape innovation pathways in an uncritical manner, make this task a highly relevant and timely one [110]. In addition, when conducted from a more socio-political and relational perspective, they could be used to shed light on the constructive dynamics of these FSs and the role they play in shaping current socio-technical arrangements and decision-making processes (e.g., tracing actors' agency in meaningassignment processes).

For example, transhumanist discourses might include speculative assumptions about the feasibility of certain NESTs' applications (e.g., nanotechnologies). They might also reflect certain values about our civilisation and the relationships we establish with our bodies and our position as a species-among-species (what values and images of science does transhumanism convey, whose values are these, what sociotechnical assumptions underpin its discourses, are they plausible and desirable?). A critical-hermeneutic analysis would also closely monitor the socio-cultural and political discourses (and actors) that motivate and strengthen these discourses (what are their socio-cultural and political roots, why are they in vogue now, what does this indicate about our societies, who wins and who loses?) (e.g., [111]) [step 3].

The information generated can subsequently help to ground more self-reflective and informed ways of performing anticipatory practices and developing a political economy of the future. The ultimate aim here is to avoid the uncritical materialisation of technological paths and co-production dynamics through uncritical (formal/informal) anticipations and deterministic ways of approaching the future. Indeed, the aim of interventive critical-hermeneutic practices within Futures Studies is to renegotiate the meanings associated with futures and to emancipate actors from anticipatory power dynamics [112] (p. 111). Similarly, some authors suggest that activities based on this critical-hermeneutic approach could contribute to the promotion of 'futures literacy' [67]. A criticalhermeneutic approach specifically focused on the normative foundations could also serve as a starting 
point for recognising the current normative state of a system and conducting the continuous normative assessment proposed by Dupuy [62] [step 4]. ${ }^{7}$

Vision assessment, which is a clear example of a critical-hermeneutic anticipatory activity, is mentioned as a valuable practice for AG [7] (p. 985) and RI [12] (p. 1571). In addition, RI emphasises that 'successful anticipation also requires understanding of the dynamics of promising that shape technological futures' [12] (p. 1571), which could be addressed through critical-hermeneutic anticipations. Moreover, the 'reflexivity' dimension of RI has both firstand second-order import. Since critical-hermeneutic anticipations are meta-representational in nature, they explicitly include in their socio-epistemic mechanisms a second-order reflection around the FSs-in-use. Although this second-order reflection could also be achieved through exploratory anticipatory processes, this is not their explicit function (its reflective potential could be limited). Given that the issue of futures is transversal for AG and RI's challenges, this mode of anticipation-as will be seen below in the dialogue with Nordmann's assessment on anticipation-is a key activity.

\section{Staying with Anticipation? Nordmann's Criticisms of the 'Future Talk' for the Governance of NESTs}

The previous section showed that anticipation is a heterogeneous socio-epistemic practice. It can adopt multiple forms and display multiple heuristics. In addition to the socio-epistemic dynamics that each modality of anticipation establishes with FSs, I have shown that while some anticipations are recognised as favourable interventive tools for AG and RI, others are not. Both AG and RI seem to exclude predictivist anticipations, while accepting exploratory and

\footnotetext{
7 The methodology of ongoing normative assessment can serve as an example of the combined character that anticipatory activities can acquire: Starting from an analysis of the state of a system and its normative assumptions (criticalhermeneutic), it aims to evaluate and reflect on them collectively and, if necessary, to create a picture of an alternative desired and plausible normative fu ture (exploratory), in order to take it as a future target for our actions (strategic). Criticalhermeneutic approaches, moreover, seem to clearly embrace a metaphysics of what Dupuy calls 'projected time'. See [62] (pp. 15-16 and 21-24).
}

critical-hermeneutic ones. RI also seems to accept strategic foresight practices (e.g., scenario planning is mentioned), while it is less clear to what extent this is also the case for AG.

This heterogeneity contrasts with the homogeneous concept of 'anticipation' that its critics typically assume (e.g., [19, 113]). As mentioned in the Introduction, I would like to concentrate here on Alfred Nordmann's assessments concerning the uses of the future to foster responsibility in R\&D. In 'Responsible Innovation, the Art and Craft of Anticipation' [19], Nordmann raises diverse concerns about anticipation and concludes that it is not necessary for AG and/or RI.

Nordmann characterises 'anticipation' as any socioepistemic activity that aims to accomplish governance of science and technology on the basis of "knowledge — no matter how tentative or qualified — of what might be the case in the future' [19] (p. 87). His assessment focuses mainly on discerning to what extent such knowledge of the future is possible, and whether it is desirable to base the governance of $R \& D$ on it. In short, he is sceptical about the possibility of knowing what will be the case, and his comments warn of the various shortcomings that a governance based on this aspiration to know about what will happen could have. From Nordmann's point of view, anticipation seems not only futile or unnecessary, but can even be (politically) counterproductive.

The concept of anticipation outlined and the analysis conducted in the previous section demonstrates that Nordmann's conception of anticipation is a narrow one, since it does not embrace in all its complexity and richness the diverse ways in which we can engage with (and use) FSs [21]. Nordmann constrains 'anticipations' to predictivist anticipations: Those whose FSs have been created and are approximated as models that attempt to minimise the uncertainty of what will be the case. Although no one can question that this is the mainstream way of interpreting anticipation (i.e., that such a mode of anticipation still prevails in the practices and discourses of $R \& D$ governance) and that it can clearly engender the problems identified by Nordmann, it is precisely this mode of anticipation that AG and RI reject or dispute and aim to respond to via other modes of anticipating.

In fact, if we approach Nordmann's text in light of the characterisations of anticipation offered here, one will find that while he considers 'anticipation' unnecessary, he accepts the heuristics of other practices that 
actually fulfil the characterisation of 'anticipation': 'Imagined alternative worlds that do not carry the burden of having to serve as possible futures can be judged without incurring the charge or paternalism'; 'scenario thinking is less encumbered and becomes more versatile, creative, and powerful if the scenarios are considered proposals for alternative socio-technical arrangements rather than possible or likely images of the future' [19] (p. 87). Indeed, Nordmann seems to advocate the need to enhance 'mind-sets that can handle contingency that can expect the unexpected and do not fall for false promises or the illusion of intellectual and technical control' [19] (p. 89), which is precisely the aim of many exploratory exercises and more explicitly of critical-hermeneutic foresight processes. For instance, Nordmann can be considered a defender of the need to approach the FSs at stake from a criticalhermeneutic angle (e.g., [23])—vision assessment is in fact, as this paper shows, a form of critical-hermeneutic anticipation.

That Nordmann assumes a narrow conception of anticipation (monopolised by a predictivist modus operandi) and seems to look favourably upon certain exercises and heuristics that have typically been seen as 'anticipatory' suggest that his diagnosis of anticipation being unnecessary for AG and/or RI ought to be relativised and nuanced.

Although Nordmann's assessment does not recognise the heterogeneity of anticipation and its underlying rationale for AG and RI [2, 20, 21], I nevertheless believe that some lessons can be drawn from his various criticisms of the 'future talk'. Indeed, these critiques touch on fundamental operational and epistemological aspects that should be considered when assessing whether each form of anticipation can be conceived as a legitimate tool for enhancing the governance of NESTs [2].

In the following sub-sections, I will use some of the criticisms against the 'future talk' raised by Nordmann as a heuristic resource. In particular, he considers that anticipatory practices, when performed under certain conditions, may (i) reify certain future perspectives (e.g., reproducing deterministic visions) ('The 'If and Then' Syndrome: Speculative Ethics and Reifying Futures'), (ii) diminish our ability to see what is happening ('Anticipations May Diminish Our Ability to See what is Happening'), and/ or (iii) reproduce the illusion of having control over the future ('Anticipations May (Re)produce an Illusion of Control Over the Future'). The first criticism is raised in 'If and Then: A Critique of Speculative NanoEthics' [17] and was exclusively directed against anticipatory speculative ethics (i.e., its target was never AG and/or RI). By contrast, the latter two criticisms are raised in 'Responsible Innovation, the Art and Craft of Anticipation' [19] and were specifically targeted against anticipation (understood in a predictivist sense) as a tool for AG and RI. Nevertheless, as they all pose challenges on the 'use of the future' and the procreation of deterministic mind-sets, I will test these critiques against the different modes of anticipation considered valuable for AG and RI (strategic, exploratory, and critical-hermeneutic) as a mere theoretical exercise.

For this very reason, the purpose of this exercise is not (and cannot be) to contradict Nordmann's criticisms. On the contrary, it is a means for exploring the potential theoretical limits of certain ways of executing each mode of anticipation that is considered valuable for AG and/or RI in the face of these possible shortcomings. The aim is to emphasise two ideas: (i) the need to focus on the conditions under which anticipatory exercises are conducted and (ii) that a criticalhermeneutic approach seems to be a robust and vital element in making anticipatory discourse and practice a more legitimate tool for 'responsibilisation'.

The 'If and Then' Syndrome: Speculative Ethics and Reifying Futures

The first criticism I would like to attend to is the one posed by Nordmann in 'If and Then' to a certain modus operandi present in speculative ethics. Although this critique was not directed at AG and RI, the exercises to which this critique is directed-as will be shown below—satisfy the definition of anticipations provided in 'Engaging with 'Futures': Basic Socio-epistemic Steps in the Performance of Interventive Anticipations'. Some important notes can be extracted from Nordmann's critiques when it comes to operationalising anticipations for AG and RI. ${ }^{8}$

Nordmann's critique of certain types of speculative ethics must be understood within the context from

\footnotetext{
${ }^{8}$ For instance David H. Guston, a renowned architect of AG, has dedicated some words to addressing Nordmann's criticisms on speculative ethics, see [14] (pp. 114-116), [9] (p. 220).
} 
which it emerged. Certain anticipatory discourses or narratives derived a series of speculative (both 'positive' and 'negative') consequences or impacts from implausible and highly speculative taken-for-granted socio-technical FSs [17, 18, 114]. This speculative spirit was (and still is) uncritically mirrored by some ethicists, and this is the main target of one of Nordmann's sharper criticisms against certain misleading ways of using $F S s$ as a means for responsibilisation: the 'if and then' reasoning syndrome.

An if-and-then statement opens by suggesting a possible technological development and continues with a consequence that demands immediate attention. What looks like an improbable, merely possible future in the first half of the sentence, appears in the second half as something inevitable [17]. (p. 32)

This criticism applies to ethical discourse "that constructs and validates an incredible future which it only then proceeds to endorse or critique" [17] (p. 31). In illustrating his position, Nordmann offers a number of concrete examples. I will mention here two [17] (p. 33):

Example 1: "If it should be possible to create a direct interface between brains and machines (X), this research threatens an invasion of privacy (A) when machines are used to read human minds (Y)". Example 2: "If molecular manufacturing were to be achievable within the next $20-50$ years (X), we need to prepare for an age of global abundance (Y) and thus a new organization of our economies (A)".

In the movement from ' $\mathrm{X}$ ' to ' $\mathrm{Y}$ ', and immediately treating ' $\mathrm{Y}$ ' as an imminent future that might raise the issue ' $\mathrm{A}$ ', the ethicist reifies an imagined future (the hypothetical ' $\mathrm{X}$ ' and ' $\mathrm{Y}$ ' are treated as a factum). Paraphrasing Nordmann: the hypothetical and abstract ' $\mathrm{X}$ ' gets displaced by a supposed actual ' $\mathrm{Y}$ '; the imagined future ' $\mathrm{Y}$ ' overwhelms the present, directing present efforts towards its treatment [17] (p. 32).

This movement seems to be misleading for Nordmann for many reasons, for instance:

(i) Because it uncritically assumes the feasibility and imminent reality of a (speculative) technological development (it assumes that ' $\mathrm{X}$ ' will be an imminent consequence of the current technological development trajectory, and that it will cause ' $Y$ ')

(ii) Because it contributes to spread strategic promises, reinforce technovisionary futures or expectations, and replicate technological determinist mind-sets; and

(iii) Because focusing on ' $\mathrm{Y}$ ' and its associated 'A, $\mathrm{B}, \mathrm{C}$ ' issues/challenges displace attention away from actual ('more pressing') concerns and needs and overshadows actual technological developments

In terms of the concept of anticipation presented in 'Engaging with 'Futures': Basic Socio-epistemic Steps in the Performance of Interventive Anticipations' (see Fig. 1), Nordmann's critique points to the illegitimacy and counterproductivity of the implementation of anticipatory (speculative) practices that take the FS substrate as granted, as an imminent pregiven 'future present' [15].

The anticipations described in example 1 and example 2 operate formally, albeit speculative in content, under a predictivist and (predictivist + ) strategic modality, respectively (Table 3). The treatment of an abstract $F S$ as an impending reality that prompts immediate concerns in the present (i.e., the reification problem), as the reconstructions in Table 3 show, requires the attribution of plausibility to the FSs as well as an extreme closure of the future (i.e., that the ethicist perceives the $F S$ as plausible ${ }^{9}$ and as a likely or as the pre-given future). As stated before, the problem of reification arises when (1) there is a process of construction/validation of an abstract FS (step 2a) as a 'likely' technical development (step $2 b$ ) that it is then (2) endorsed or critiqued (step 3) [17] (p. 31).

Leaving aside the debate on the usefulness of these $F S s$ when approached not as prognoses but as explorative cases [117], here I am interested in highlighting some remarks from Nordmann's assessment that might be useful for AG and RI. The reification problem is not a phenomenon restricted to the use of speculative $F S s$, but may also be present in cases where the attribution of plausibility to $F S$ may be

\footnotetext{
9 As Lucivero, Swiestra, and Boenink note, '[t]he concept of 'plausibility' is inherently intersubjective: a statement is plausible when it makes sense to a specific audience' [115] (p. 138). See also [116, 135, 137].
} 


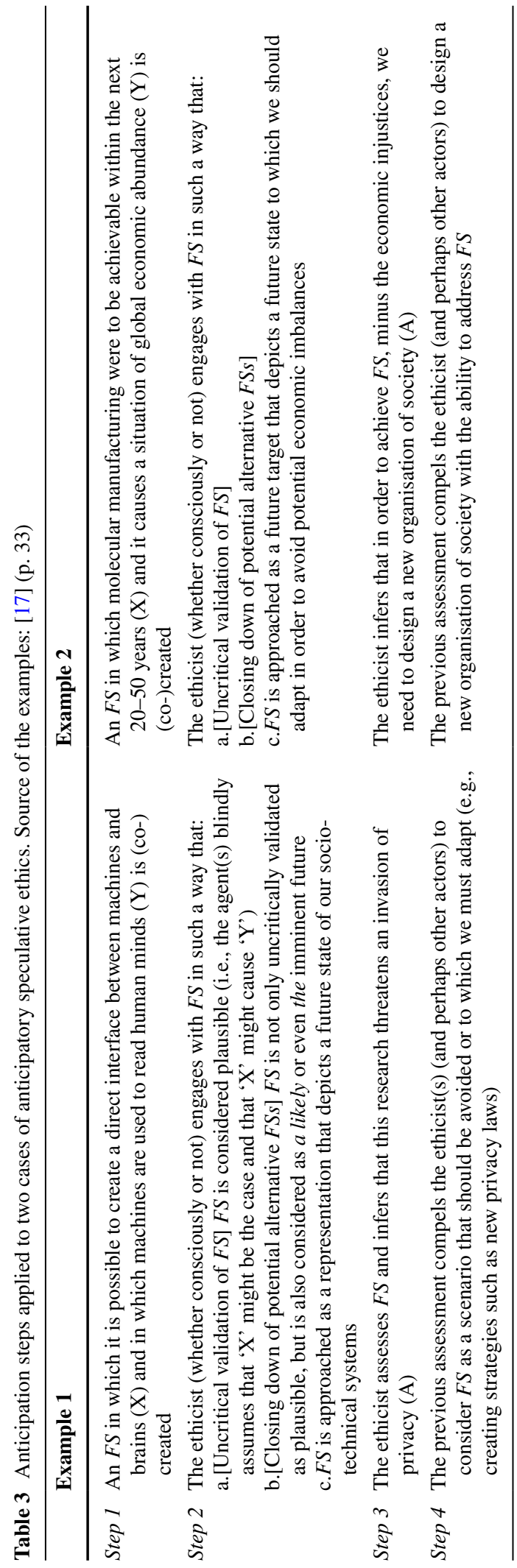

wellfounded - the fact that the reified FSs are speculative and implausible only makes the reification problem more acute.

Indeed, reification is at the heart of anticipatory practices grounded on a predictivist approach to FSs, especially when these are applied to social conditions [118]. As Nordmann notes, these predictivist projective FSs do not embrace the causal complexity of socio-technical systems. They subtly neglect the historical contingency that characterises any socio-technical development, limiting our understanding and conceptualisation of our socio-technical world as it de facto co-evolves: messy, unpredictable, indeterminate (contingent), and somehow open to limited interventive action. The criticism of reification is basically a criticism of the malpractices that may result from functioning under determinist mind-sets.

The critique of reification may be relevant to AG and RI as it invites us to problematise the FSs that are taken into consideration (and their underlying assumptions). The critique can also serve to deflate the possible ontological or epistemic commitments we might have towards FSs. This implies, for example, that if RI understands anticipation as 'What if' questions, the 'ifs' must be themselves taken as the very object of scrutiny, as far as these fix the subject of the discussion.

Even the basic strategic question of 'What kinds of nanotechnological developments should we promote (causal driver) if we want to promote sustainable cities (FS-target)?' is framed around the limits of easily identifiable assumptions (e.g., the very fact that nanotechnology will/must be developed, the scope of the discourse is limited on cities, to focus on a technical element to solve a problem that is also socio-political and cultural). As far as any fixed FS around a NEST is itself an abstraction (it points to not-yet-existing entities), to subtly consider them as a fixed normative target towards which we should direct our present supposes an act of reification. Naturally avoiding any kind of reification can be difficult in strategic practices (given the need to pre-set an FS-target as an operative condition). Nordmann's 'if and then' critique can be read as a warning to be careful about what assumptions and FSs we consider and with which visions, expectations, and world projects these align.

The problem of reification, however, can be minimised in (and through) exploratory anticipations 
(both product-based and especially procedural). This is so because these exercises, in addition to the shared methodological call for a 'reality check' $[5,22,82$, $83,91,117,119]$ (thus minimising overly speculative $F S s$ ), collectively diversify the FSs considered and amplify the possibilities taken into account by recognising the uncertainty inherent to socio-technical and/ or techno-moral co-evolution processes (against step $2 b$, Table 3). This diversification, especially when divergent but plausible scenarios come into play, helps to highlight that there is no such thing as a fixed future. However, the degree of reification that might occur and which futures are (not) ${ }^{10}$ reified depend largely on the specific socio-epistemic dynamics that are developed in the situated and concrete anticipatory exercise, as well as on the technique used. As Boenink [2] (p. 157) notes, some techniques may be more likely to produce reifications than others; yet, there is always some room within explorative anticipatory techniques for steering critical discourses which can help to avoid the reification of certain FSs. Obviously, this process of 'steering' critical discussion and attempting to 'reconfigure intent and hence action, now and in the future' [91] (p. 734) is not without problems and tensions.

Although exploratory exercises, if well conducted, can be conceived as a valuable tool to visualise alternatives and reflect on the FSs that colonise and overwhelm the present, any exploratory exercise entails taking some assumptions as given (and discarding others). Which ones should we accept, and why? Precisely to avoid the uncritical reification of certain assumptions (descriptive and normative) and FSs, Nordmann [17], Grunwald [99] Lucivero, Swierstra and Boenink [115], and others (see also Dupuy [62]) propose to commence with a critical-hermeneutic approach: 'an ethics beholden to present capabilities, needs, problems, and proposed solutions will begin with vision assessment' [17] (p. 41). The very rationale of critical-hermeneutic anticipation consists in analysing and assessing (on the basis of currently available information and knowledge) the $F S s$ '

\footnotetext{
10 It is important to note that there may be contexts in which the lack of reification of certain FSs can be seen as unfavourable. The case of the FSs on the impacts of climate change and the failure to understand them not as abstract entities but as an immanent global-scale future can serve as an example here.
}

plausibility and desirability [109] that are assumed as given. In fact, practices such as vision assessment, which involves a critical-hermeneutic approach to future representations, require analysis and a questioning of what (and why) FSs are constructed and used as meaning-giving instruments in current $R \& D$ dynamics and practices [20].

As far as some degree of reification seems inevitable, the problem is not so much reification per se, but rather uncritical, or unproblematised, and nonlegitimised reification and closure of the future [118]. The objective is to build reflexive capacities that help to resist the uncritical reification and foreclosure of the future-making practices performed in the present. And the critical-hermeneutic approach seems-at least theoretically-like a good candidate for systematically and explicitly pursuing this goal.

Anticipations May Diminish Our Ability to See what is Happening

Another argument put forward by Nordmann, which strongly connects with the previous point, claims that working with (often speculative) FSs can diminish our ability to see what is happening. The 'if and then' syndrome 'deflects consideration from the transformative technologies of the present' [17] (p. 31). Engaging with speculative scenarios like the ones presented in the previous section (examples 1 and 2) not only reifies the $F S s$ they portray, but also serves 'only to distract us from comparatively mundane, yet no less important and far more pressing issues' [17] (p. 43).

The reason why the 'future talk' diminishes our ability to see what is happening seems to be twofold. On the one hand, since intellectual resources and attention are scarce resources, Nordmann considers that these must not be squandered on incredible, reifying, and distracting FSs [17] (p. 34), [114]. On the other hand, a cognitive state of 'living in the future' can dispose us to farsightedness (i.e., to miss the $\mathrm{R} \& \mathrm{D}$ issues that are happening here and now). While the first issue relates to normative concerns about where and to what extent intellectual resources and attention should be placed (whether in technologies yet to be developed and whose effects can only be speculated upon or in technologies at more advanced stages of development), the second issue directly appeals to a possible counterproductive effect of interventive anticipations. 
As noted in 'NESTs 'Responsibilisation' and the Call for anticipation: Anticipatory Governance and Responsible Innovation', AG and RI are committed to an early social intervention which has to be 'welltimed so that they are early enough to be constructive but late enough to be meaningful' [12] (p. 1571). However, this sense of opportunity, as Grunwald notes, must be situated in contexts of uncertainty where it is difficult to discern which technologies and problems might be relevant for early analysis and governance [117] (pp. 94-95). Furthermore, the consideration of which technologies are considered relevant for assessment in the present is often modulated by expectations and visions. Visions and expectations play a part in determining which technologies/NESTs will be taken as objects of responsibilisation [58].

The question of which area of research and development to intervene in is not trivial. It has been convincingly argued that the need to use more or less future-oriented activities depends largely on the specific situation and the stage of development of the technology/innovation to be analysed $[1,79]$. On the one hand, participating at an early stage in the governance of a NEST riddled with much-hyped promises and wonders/horrors somehow involves being part of (and benefiting from) the same technovisionary dynamics that point to the need to make such technology an object of responsibility. On the other hand, not to intervene in these technovisionary dynamics (i.e., not trying as far as possible to enhance reflexivity within the co-production of the NEST) would be to embrace passivity [120]. The criticism against speculative ethics concerning the misallocation of resources becomes a challenge when extrapolated to AG and RI (which Nordmann did not do). It invites self-reflection on the anticipatory discourses in which AG and RI scholars become involved, the incentives that motivate this involvement, and its possible consequences.

In a more general tone (i.e., referring not only to speculative ethics), Nordmann states in 'The Art and Craft' that 'trying too hard to imagine possible or plausible futures may diminish our ability to see what is happening' [19] (p. 88). A cognitive state of 'living in the future' can distract us from seeing what is right in front of our eyes. While in 'If and Then' the farsightedness criticism was directed at a hyperbolic and speculative (mis)use of the future by some ethicists (e.g., in the field of anticipatory bioethics [121]), in 'The Art and Craft' Nordmann's worries seem to extend to the use of anticipation in AG and RI.

One might begin to recognise that the risk of a misleading 'temporal displacement' actually exists with any exercise that involves emphasising one particular temporal tense. Even when the three temporal tenses (past, present, and future) are inherently intertwined, focusing on one of them too much can lead to downgrading the rest. For instance, a cognitive state of 'living in the past' can also dispose us to miss what is happening in the present, as well as to miss opportunities to imagine alternative better futures. Similarly, concentrating strictly on the present can deprive us of valuable lessons we can learn from engagements with the past and imagined futures. Our actions are the result of the interweaving of multiple temporalities, and to achieve a productive balance between these temporalities in foresight and interventive anticipatory exercises is a necessary, albeit not straightforward, task.

One should acknowledge that the 'temporal displacement' risk exists [91] (p. 735)—although limited in space and time-in both strategic and exploratory interventive anticipations. Whether the emphasis is on the future, the present, and the past and the relationships established between them will depend on the cognitive and socio-epistemic dynamics mobilised during the practice in question. The degree of distancing from the present (and the past) can vary, depending on the dynamics of each exercise. ${ }^{11}$ For instance, strategic anticipatory practices require setting an $F S$ as a target and continuously modulating present actions in line with its pursuit/avoidance and according to present information and analogies based on past experience. Although this could decrease the degree of farsightedness, the attention to the present could be limited to those aspects that are deemed relevant for the pursuit/avoidance of the FS target (missing potentially relevant information for a better understanding of the current general situation).

In the case of exploratory modes of anticipation, the quality criteria to be met during the construction phase of their respective $F S s$ typically requires

\footnotetext{
11 The existence of the problem of temporal dislocation has prompted the emergence of perspectives that call for the interpretation of foresight as 'an instantiation of temporal reflexivity', which would imply taking all three temporal orders into consideration simultaneously and continuously $[122,123]$.
} 
knowledge of the past and present situations. In this sense, the degree of farsightedness will depend on the negotiation dynamics of $F S s$ ' plausibility. If performed well, exploratory exercises may even serve to contextualise, map, problematise, enrich, and/or raise awareness of the different perspectives concerning the current and potential future state of affairs as well as identify analogous past situations.

The practices of anticipation in which the connection with the present is most radical and evident are obviously the critical-hermeneutic (again, this explains why Nordmann and other scholars argue for the need to take this approach as the starting point of any process engaging with $F S s$ ). Rather than displacing the present and diminishing our ability to see what is happening, adopting a critical-hermeneutic approach would situate us in the present: the objective is to take the co-existing $F S s$ as products that reflect the contingent temporal horizon from which they have emerged.

Anticipations May (Re)produce an Illusion of Control Over the Future

The third and final considered criticism holds that anticipatory practices could create the illusion that we have some intellectual and/or technical control over the future. Confronted with this illusion, Nordmann stresses that instead of promoting anticipation, we need to emphasise the contingency that constitutes the co-evolution of socio-technical systems [19] (p. 89). As a careful look at the history of technology could certainly remind us, many non-predictable coevolutions of science, technology, and society have been surprising. Against this background, the practice of anticipation might seem not simply futile, but counterproductive: for Nordmann, it (re)produces a mind-set in which the future is taken as a controllable object of design.

To what extent do the anticipatory practices considered valuable for RI and AG reproduce an illusion of intellectual and/or technical control over the future? The FSs on which strategic anticipations are based and the 'guidelines for action' derived from them can be interpreted from different perspectives. For example, the $F S$ s serving as substrates can be understood from fixed and de facto achievable targets, to FSs whose function is merely heuristic (i.e., as regulative ideal targets). In a similar way, the 'guidelines for action' derived from these exercises can be interpreted from rigid norms (which must be strictly adhered to and whose effective safeguarding can lead us towards a fixed future), to flexible orientations (which define some practical options for action, but do not guarantee the achievement of the desired future target).

The degree of control (and contingency or surprise) that strategic anticipatory practices can assume will largely depend on the positioning of the actors who implement them in relation to these variables. In other words, the question of whether strategic anticipatory practices reproduce the illusion of control over the future will depend on a number of highly contingent factors that are determined by the dynamics and perspectives from and through which these anticipatory practices are approached and constructed. Although there is a risk that normative anticipatory practices (re)create the illusion of intellectual and technical control over the future, this critique could be minimised by building these practices on mechanisms that recognise and/or emphasise the contingency, fallibility, and openness that characterise (a broad spectrum of) human actions.

Exploratory anticipatory practices are less likely to (re)create the illusion of epistemic and/or technical control over the future because of their less epistemic and normative ambitions: their aim is not to define addressable future goals, but rather to open up or enrich the space of the FSs considered plausible and/or desirable in the present. It is precisely in the processual exploratory anticipatory practices that the emphasis is placed on the plurality of available options and/or the diversity of points of view with the aim to enrich not only the different sociotechnical and techno-moral paths and/or projects that could actually be considered, but also their contingency and possible variability (i.e., learning that the future might always be otherwise [124]).

The success of the exploratory anticipatory heuristics will largely depend on the level of reflection on the dynamics that underlie (and constitute) these socio-epistemic activities-which in turn may depend on many other variables, such as the actors involved (and the relations established between them). In this respect, the integration of a criticalhermeneutic approach in the undertaking of exploratory exercises, as Nordmann notes, would be particularly helpful. For instance, a critical-hermeneutic approach would impel us-beyond the provision of 
information through the explicit analysis and evaluation of the assumptions and meanings of the FSs in question-to place these FSs in concrete spatiotemporal horizons and contextualise them in the light of history and the socio-political landscape from which they emerge.

Such historical contextualisation and anchoring to the present could help to relativise our expectations and dreams (including those related to the realisation of AG and RI's goals) without at the same time neglecting the capacity for action we have for the governance of sociopolitical systems. Even if the co-evolution of social, moral, and technical systems eludes our overall control to an extent, we can still influence them in the best possible way, taking into account the resources currently available. Strategic, exploratory, and especially criticalhermeneutic anticipatory practices, in many respects, seem to constitute such a resource.

In 'A Forensics of Wishing: Technology Assessment in the Age of Technoscience' [30], for instance, Nordmann urges us to approach any exercise involving $F S s$ with an eminently historical conception of the future, while considering the contingency and precariousness of our present knowledge (a conception of the future which, for him, is in contrast to that anchored in the age of technoscience): 'Given that our sphere of influence is limited to the present, it is an impossible dream to control the future development of technology; wanting to do so anyhow is a technoscientific conceit' [30] (p. 11).

In order to avoid AG and RI falling into the hubris of technoscience, it would be positive for these frameworks to assume as a starting point the maxim that Sardar has already established for 'Future Studies' when operationalising foresight/anticipation. Anticipation is, somewhat counterintuitively, a futureless activity in the technical sense: the relevance of its discourse, tools (such as foresight/anticipation), and fruits (anticipatory heuristics) lies in the present [125]. As such, the FSs on which anticipation works should not be interpreted as representations denoting what will be the case (predictivist approach), but rather as constructs that express what we currently believe will be the case (and how we frame that future) - under the consideration of certain assumptions. It is precisely those assumptions and frames of thought about the future and not the future per se that comprise the objects of analysis, scrutiny, and negotiation within foresight practices [116].

\section{Responsibility through the Search for the Future's Plausibility and Desirability}

The previous theoretical analysis noted Nordmann's concerns about how certain practices that engage with 'the future' may have an effect on different modes of anticipations at different levels and depths. For instance, the analysis shows not only that criticalhermeneutic anticipations are not affected by these pitfalls but also that they seem to contribute to avoiding them. In fact, the emergence of the critical-hermeneutic approach can be read in the light of the attempt to evade and respond to the misuses of the future that underlie the above criticisms (which 'explains' why Nordmann himself is an advocate of this mode of anticipation).

His conclusion on the futility of anticipa tions for AG and RI can then be nuanced, and (re-)interpreted as an argument that speaks to the importance of performing anticipations that include and begin with a critical-hermeneutic approach-whether alone or in combination with the other modes of anticipation that AG and RI consider worthwhile (i.e., the strategic and exploratory modes). Nordmann's critical points can be rethought not as a means to refute the value of anticipation (understood in a broad sense), but as an invitation to perform better anticipatory practices: ones in which our FSs are contextualised and subjected to continuous scrutiny and in which any denotative pretentiousness is continuously deflated.

In addition, the previous analysis yields another result: Although each mode of anticipation, in virtue of their specific socio-epistemic modus operandi and functionalities, is more or less susceptible to fall prey to the shortcomings analysed, to ultimately judge the possible value of anticipation for AG and RI requires realtime and socio-epistemic empirical scrutiny. How are anticipations configured, and how are each of its constitutive socio-epistemic steps performed? What kinds of socio-epistemic and political dynamics do they help to generate? This implies that we cannot always totally determine in an aprioristic or pure th eoretical manner whether anticipations are (not) a 'legitimate' or worthwhile socio-epistemic tool for AG and RI. Rather, we need to assess how each mode of anticipation is performed in practice. Before anticipations are taken on as an instrument for 'responsibilisation', 
it is necessary to make their methodological design ${ }^{12}$ and constitutive socio-epistemic dynamics (from step 1 to step 4) objects of responsibility [93, 126].

One process that implicitly or explicitly exerts a strong influence on the socio-epistemic steps of anticipatory practice is that of scrutinising and collectively negotiating the plausibility and desirability of the FSs under consideration. On the o ne hand, this process determines what information is (not) considered in the extraction of the information/heuristics from $F S$ (i.e., in step 3; see Fig. 1). Only those FSs that are considered plausible and/or (un)desirable are considered an epistemic substrate for orienting action (step 4). On the other hand, qualifying and evaluating FSs and the assumptions on which these are built as 'implausible' may lead to their de- or reconstruction, producing alternative ones or refining or correct ing tho se that are currently available (thus $r$ eactivating steps 1 and 2 of the anticipatory process; see Fig. 1). The evaluation of (im)plausibility and (un)desirability can be considered as the socio-epistemic device that both expands and narrows the space of the FSs considered in anticipatory practices [116].

If the general objective pursued by RI and AG through anticipatory exercises is precisely to collectively problematise the ends towards which research and innovation are directed, and to examine ex ante the possible risks and socio-technical configurations that could arise from the development of a particular line of scientific and technological research, it seems reasonable to assume that the considerations of the (un)desirability and (im)plausibility of these futures is a crucial point.

The determination of the (un)desirability and (im) plausibility of the FSs will largely depend on whether these reflect or are consistent with the beliefs, axiology, hopes, or interests shared by the actors involved in their co-production and/or co-assessment. Each (group of) actor(s) will consider an $F S$ to be more

\footnotetext{
12 As with any other interventive tool, the methodological definition and refinement of each mode of anticipation ought to be performed according the pursued objective, intended area of application, actors involved, etc. These methodological concretisations can have different levels of idealisation/specificity. Moreover, the inherently contingent and fallible nature of interventive anticipatory practices prevents us from assuming that, even if the methodological characterisation and the corresponding translation into practice are properly performed, the expected heuristics will necessarily emerge.
}

or less (un)desirable or (im)plausible on the basis of (i) the normative and epistemic assumptions they hold at that moment, (ii) how they associate these assumptions, and (iii) how they infer from them what is (not) reasonable/desirable to be expected in the future. Despite the possible existence of common and shared normative and empirical stances (both of which are often intertwined [127]), it seems reasonable to expect that many of these will diverge. The plurality and variability of normative, theoretical, and/or empirical resources and assumptions (about the past, the present, and the future) that the different actors might possess, together with the different ways of relating or framing them and drawing conclusions, configure different registers of what each (group of) actor(s) might consider a (un)desirable/ (im)plausible $F S$. As a result, a wide range of (un) desirable and/or (im)plausible FSs could co-exist and compete.

While these divergences could be considered heuristically positive for illuminating alternative action targets or socio-technical/techno-moral co-evolution paths, they can also (due to the existence of irreconcilable values, interests, or beliefs) hinder the communication and consensus required for orienting decisionmaking [128]. Moreover, even when the option to transform the tension produced by diversity and divergence into a productive and creative social learning exists, the procedural/formal nature of AG and RI and anticipatory exercises does not provide a mechanism for assessing the legitimacy of the judgements that might support the different options [90]. The assumptions and the cognitive and logical processes used to articulate and to project conclusions from them can arguably have different robustness gradients, and therefore the attributions of (un)desirability/(im)plausibility can be more or less justified.

The development of some standards to evaluate the information, values, and the reasoning/argumentative processes that support the attribution of (un)desirability and (im)plausibility seems to be of central importance. However, again, this is not without tensions. Because these standards establish the basic (meta-) rules of what is considered epistemically and normatively 'valid', they constrain ex ante which of the $F S$ s deemed desirable or undesirable are legitimised to be part of the deliberative process. In this respect, one might argue that there may be certain minimum values and epistemic stances that could preserve 
legitimacy over space and time. For instance, Ruggiu proposes Human Rights [129, 130] as the normative minimum basis for anticipations. However, the minima are usually capable of accommodating a large number of dissimilar concrete alternatives. For example, we could envision different models of society that, while satisfying the minimum of human rights, politically encapsulate different social orders or relations with nature.

These methodological, epistemic, and ethico-political difficulties regarding the establishment of 'the (un)desirable' and 'the (im)plausible' appear when the focus of these criteria is on their limiting role (i.e., when they are understood as criteria which function to constrain the space of FSs that should be considered as substrates in anticipatory practices). In other words, the previous problems arise when the responsibilisation of anticipation is focused on assuring a minimum epistemic and normative quality of the FSs that are used to guide our actions in the present.

However, the emphasis on the limiting role of (im) plausibility and (un)desirability—regardless of how relevant and important this is - needs to be complemented by also paying attention to the other function that these criteria (aim to or could) play: the reflective or disruptive one. Here, the establishment of 'the (un)desirable' and 'the (im)plausible' functions to open up the FSS under consideration. By discussing and reflecting on the '(un)desirability' and/or '(im)plausibility' of the $F S$ s, the aim is not just to perform anticipation on the basis of $F S s$ that meet a set of qualifiers or standards, but to shape a second-order reflection on the standards themselves: on the basis of which values, knowledge, assumptions, and frames of thought does the (co-)construction/(co-)evaluation of futures take place?

The enactment of the second role of plausibility requires the identification and clarification of the assumptions and processes at work within the deliberative processes that support the attribution of (un)desirability or (im)plausibility, which inevitably requires the inclusion of a critical-hermeneutic approach within strategic and exploratory anticipatory practices. This involves identifying and considering which actors, knowledge, and assumptions have been considered/excluded when establishing the arena of 'the (im)plausible' and/or 'the (un)desirable' and on what basis. In a landscape where, as Nordmann notes, 'actors are trying to persuade each other of what to take seriously' [18] (p. 130), the existence of exclusion mechanisms (e.g., epistemic [131] or argumentative $[132,133]$ injustices) and power dynamics that permeate and shape the discursive spaces [134] should be the focus for responsibilising anticipations. It is precisely the socio-epistemic quality of the argumentative and reasoning dynamics that shapes the construction/assessment of the (un)desirability and (im)plausibility of the FSs that will define the potential degree of reflexivity and disruptiveness of the heuristics derived from the anticipatory exercises. These heuristics can become operative afterwards (in step 4) with different levels of strength, and they can be finally materialised depending on a series of factors influencing whether and how these (un)desirable/ (im)plausible FSs finally mobilise action [135].

The inclusion of a critical-hermeneutic perspective within the strategic and explorative anticipatory dynamics will not resolve the noted tensions, but it might help to reveal the power relations and the existing rhetoric and argumentation patterns that destabilise the balance towards the acceptance of certain arguments or anticipatory discourses in the defence and articulation of the '(im)plausibility' and '(un)desirability' of certain futures. The introduction of a criticalhermeneutic approach within the iterative processes of (co-)construction and (co-)evaluation of the FSs could not only be a necessary (but non-sufficient) condition for preventing anticipatory practices from falling prey to Nordmann's fears of misuse of the future; it may also contribute to steer reflexivity in the process through which arguments and reasons in support of particular FSs are developed and established.

\section{Conclusions}

Anticipation has always been a central activity for science and technology policy frameworks. Following this tradition and taking into account a variety of approaches and practices (e.g., RTTA, vision assessment), AG and RI frameworks explicitly refer to the need for 'foresight' and a range of other intervening anticipatory practices. These practices aim to address and reflect on a range of challenges related to the ongoing governance of science and technology at the early stages of development in order to increase the responsiveness of their processes, motivations, and outcomes ('NESTs 'Responsibilisation' and the Call for Anticipation: Anticipatory Governance and Responsible Innovation'). 
Notwithstanding the functional value of anticipation in operationalising the concept of procedural responsibility that these frameworks convey, the description of the kinds of engagements with the future that these processes are designed to enable has remained less explicit. This lack of explicitness and conceptual grounding of anticipation, combined with the fact that the predominant way of relating to the future is as a space that needs to be cognitively grasped or designed, has led to the emergence of various critiques that question the value of anticipation.

Based on this diagnosis, this article has attempted to move forward in the conceptualisation of anticipation, paying particular attention to the critique of various misuses of the future identified by the philosopher Alfred Nordmann. Such misuses include the possible reification of futures, the diminution of our capacity to know what is happening, and the reproduction of the illusion of intellectual or technical control over the future. The first critique is directed at anticipatory speculative ethics, while the second and third criticisms extend to anticipation as a tool of AG and RI.

Specifically, starting from a basic concept of anticipation, I distinguished between four different modes of anticipation, each grounded in different approaches to the future: predictivist, strategic, exploratory (in its 'product-based' or 'processual' genre), and critical-hermeneutic. Each of these modes of anticipation involves the generation of different socioepistemic dynamics and they can provide differentiated heuristics. In relation to these four modalities, it was noted that AG and RI view some of them negatively (e.g., the predictive in AG and RI and perhaps the strategic in AG) and others more positively (e.g., the exploratory and critical-hermeneutic in AG and RI and the strategic mode in RI) ('On Four Approaches to 'The Future' and Four Corresponding Modes of Anticipation').

This analysis enabled us to note that Nordmann's contention that anticipation is not a necessary activity for AG and RI is based on a narrow conception of anticipation in which anticipation is limited to its predictive modality (i.e., the very modality that RI and $A G$ reject as useful for operationalising their concept of anticipation) ('Staying with Anticipation? Nordmann's Criticisms of the 'Future Talk' for the Governance of NESTs'). Despite the fact that Nordmann's characterisation of anticipation is not broad enough, his criticisms of anticipation and speculative ethics (the 'future talk'), when heuristically extrapolated against the modes of anticipation considered valuable for AG and RI, provide some interesting results ('The 'If and Then' Syndrome: Speculative Ethics and Reifying Futures', 'Anticipations May Diminish Our Ability to See What is Happening', 'Anticipations May (Re)produce an Illusion of Control Over the Future'). These results can be summarised as follows:

(i) That each mode of anticipation is (not) susceptible to Nordmann's worries (reification, diminishing our ability to see what is happening, and/or reproducing the illusion of control over the future) at different degrees and depths. In order to be more conclusive, there is thus a need to attend to how each interventive practice unfolds in practice (i.e., we need to turn our focus towards the dynamics that constitute interventive anticipations). While making foresight/anticipation an instrument for responsibilising $\mathrm{R} \& \mathrm{D}$, it must simultaneously become an object of responsibilisation [136].

(ii) That Nordmann's critiques do not compromise critical-hermeneutic anticipation; indeed, this modality of anticipation even seems to be a robust means of avoiding such critiques. The critical-hermeneutic approach (defended by Nordmann and others) finds, in its multiple justifications, an attempt to avoid the critical reification of futures, to emphasise the contingency of the present, and to contribute to a better understanding of what is happening on the basis of an analysis of the FSs at stake and their constructive dynamics.

A brief elaboration on '(i)' and '(ii)' stressed the importance of addressing the negotiation dynamics of the quest for plausibility and desirability of the FSs that constitute anticipation exercises. One of the issues that requires special attention in implementing this responsibilisation of interventive anticipations is the dynamics by which the (im)plausibility and (un)desirability of the FSs that articulate them are determined. This responsibilisation should focus not only on the limiting role of 'the (im)plausible' and 'the (un)desirable' (i.e., on restricting the spectrum of futures under consideration to those that meet 
minimum, pre-established quality standards), but also on their enabling role (i.e., on preventing exclusionary rhetoric and power regimes that unfairly exclude the consideration of alternative or disruptive plausible and/or desirable futures, thus encouraging scrutiny of the standards themselves) ('Responsibility Through the Search for the Future's Plausibility and Desirability').

Acknowledgements The author would like to thank the anonymous reviewers for their helpful and constructive comments that greatly contributed to improving the final version of the manuscript.

Funding Open Access funding provided thanks to the CRUECSIC agreement with Springer Nature. Open Access funding provided by the University of the Basque Country UPV/EHU thanks to the CRUE-CSIC agreement with Springer Nature. The current article was written during a research stay at the University of Twente (Dept. of Philosophy). The author acknowledges support from the Spanish Ministry of Industry, Economy and Competitiveness (Government of Spain) and the European Regional Development Fund under Grant BES-2016-079192, and from the Vice-rectorate for Research of the University of the Basque Country UPV/EHU under Grants PPGA19/23 and GIU19/051. Any shortcomings remain the responsibility of the author.

\section{Declarations}

Conflict of Interest The author declares no co mpeting interests.

Open Access This article is licensed under a Creative Commons Attribution 4.0 International License, which permits use, sharing, adaptation, distribution and reproduction in any medium or format, as long as you give appropriate credit to the original author(s) and the source, provide a link to the Creative Commons licence, and indicate if changes were made. The images or other third party material in this article are included in the article's Creative Commons licence, unless indicated otherwise in a credit line to the material. If material is not included in the article's Creative Commons licence and your intended use is not permitted by statutory regulation or exceeds the permitted use, you will need to obtain permission directly from the copyright holder. To view a copy of this licence, visit http://creativecommons.org/licenses/by/4.0/.

\section{References}

1. Brey PAE (2012) Anticipatory ethics for emerging technologies. NanoEthics 6(1):1-13. https://doi.org/10.1007/ s11569-012-0141-7

2. Boenink M (2013) Anticipating the future of technology and society by way of (plausible) scenarios: Fruitful, futile or fraught with danger. Int J Foresight Innov Policy. 9 (2/3/4):148-161. https://doi.org/10.1504/ijfip.2013.058608
3. Guston DH, Sarewitz D (2002) Real-time technology assessment. Technol Soc 24(1-2):93-109. https://doi. org/10.1016/s0160-791x(01)00047-1

4. Grunwald A (2019) The inherently democratic nature of technology assessment. Sci Pub Policy 46(5):702-709. https://doi.org/10.1093/scipol/scz023

5. Swierstra T, Stemerding D, Boenink M (2009) Exploring techno-moral change: The case of the obesitypill. In: Sollie P, Düwell M (eds) Evaluating new technologies. The international library of ethics, law and technology. Springer, Dordrecht, pp 119-138. https://doi.org/10. 1007/978-90-481-2229-5_9

6. von Schomberg R, Guimarães Pereira Â, Funtowicz S (2005) Deliberating foresight knowledge for policy and foresight knowledge assessment. Office for Official Publications of the European Communities, Luxembourg

7. Barben D, Fisher E, Selin C, Guston DH (2008) Anticipatory governance of nanotechnology: Foresight, engagement, and integration. In: Hackett EJ, Amsterdamska O, Lynch M, Wajcman J (eds) The handbook of science and technology studies, vol 3. MIT Press. Cambridge, MA, pp 979-1000

8. Karinen R, Guston DH (2009) Toward anticipatory governance: The experience with nanotechnology. In: Kaiser M, Kurath M, Maasen S, Rehmann-Sutter C (eds) Governing future technologies. Springer, Dordrecht, pp 217232. https://doi.org/10.1007/978-90-481-2834-1_12

9. Guston DH (2014) Understanding 'anticipatory governance.' Soc Stud Sci 44(2):218-242. https://doi.org/10. 1177/0306312713508669

10. Owen R, Macnaghten P, Stilgoe J (2012) Responsible research and innovation: From science in society to science for society, with society. Sci Public Policy 39(6):751-760. https://doi.org/10.1093/scipol/scs093

11. Owen R, Stilgoe J, Macnaghten P, Gorman M, Fisher E, Guston D (2013) A framework for responsible innovation. In: Owen R, Bessant JR, Heintz M (eds) Responsible innovation. Wiley, Chichester, pp 27-50. https://doi. org/10.1002/9781118551424.ch2

12. Stilgoe J, Owen R, Macnaghten P(2013) Developing a framework for responsible innovation. Res Policy 42(9):15681580. https://doi.org/10.1016/j.respol.2013.05.008

13. Owen R, Pansera M (2019) Responsible innovation and responsible research and innovation. In: Simon D, Kuhlmann S, Stamm J, Canzler W (eds) Handbook on science and public policy. Edward Elgar Publishing, Cheltenham Northampton, MA, pp 26-48

14. Guston DH (2013) "Daddy, can I have a puddle gator?": Creativity, anticipation, and responsible innovation. In: Owen R, Bessant JR, Heintz M (eds) Responsible innovation: Managing the responsible emergence of science and innovation in society. Wiley, Chichester, pp 109-118

15. Adam B, Groves C (2007) Future matters: Action, knowledge, ethics. Brill, Leiden, Boston

16. Adam B, Groves C (2011) Futures tended: Care and future-oriented responsibility. Bull Sci Technol Soc 31(1):17-27. https://doi.org/10.1177/0270467610391237

17. Nordmann A (2007) If and then: A critique of speculative nanoethics. NanoEthics 1(1):31-46. https://doi.org/ 10.1007/s11569-007-0007-6 
18. Nordmann A (2013) (Im)plausibility ${ }^{2}$. Int J Foresight Innov Policy. 9 (2/3/4):125-132. https://doi.org/10.1504/ ijfip.2013.058612

19. Nordmann A (2014) Responsible innovation, the art and craft of anticipation. J Responsible Innov 1(1):87-98. https://doi.org/10.1080/23299460.2014.882064

20. van der Burg S (2014) On the hermeneutic need for future anticipation. J Responsible Innov 1(1):99-102. https://doi.org/10.1080/23299460.2014.882556

21. Selin C (2014) On not forgetting futures. J Responsible Innov 1(1):103-108. https://doi.org/10.1080/23299460. 2014.884378

22. van der Burg S (2010) Ethical imagination: Broadening laboratory deliberations. In: Roeser S (ed) Emotions and risky technologies. Springer, Dordrecht, pp 139-155

23. Nordmann A (2013) Visioneering assessment. On the construction of tunnel visions for technovisionary research and policy. Science, Technology \& Innovation Studies (STI). 9(2):89-94

24. Coates JF (1971) Technology assessment: The benefits... the costs... the consequences. The Futurist 5:225-231

25. Enzer S (1972) Cross-impact techniques in technology assessment. Futures 4(1):30-51. https://doi.org/10.1016/ 0016-3287(72)90023-7

26. Rip A, Misa TJ, Schot J (1995) Managing technology in society: The approach of constructive technology assessment. Pinter Publishers, London

27. Arnaldi S, Gorgoni G (2016) Turning the tide or surfing the wave? Responsible research and innovation, fundamental rights and neoliberal virtues. Life Sciences, Society and Policy 12(1):6. https://doi.org/10.1186/ s40504-016-0038-2

28. VanEijndhoven JCM(1997)Technology assessment: Product or process? Technol Forecast Soc Chang 54(2):269-286. https://doi.org/10.1016/S0040-1625(96)00210-7

29. Grunwald A (2009) Technology assessment: Concepts and methods. In: Meijers A (ed) Philosophy of technology and engineering sciences. North-Holland, Amsterdam, pp 1103-1146. https://doi.org/10.1016/B978-0-44451667-1.50044-6

30. Nordmann A (2010) A forensics of wishing: Technology assessment in the age of technoscience. Poiesis Prax 7(1):5-15. https://doi.org/10.1007/s10202-010-0081-7

31. Arthur WB (1989) Competing technologies, increasing returns, and lock-in by historical events. Econ $\mathrm{J}$ 99(394):116-131. https://doi.org/10.2307/2234208

32. Collingridge D (1980) The social control of technology. Francis Pinter Ltd, London

33. Jasanoff S (1996) Beyond epistemology: Relativism and engagement in the politics of science. Soc Stud Sci 26(2):393-418. https://doi.org/10.1177/030631296026002008

34. Rip A, Kemp RPM, Kemp R (1998) Technological change. In: Rayner S, Malone EL (eds) Human choice and climate change, vol 2. Resources and Technology. Battelle Press, Columbus, Ohio, pp 327-399

35. Fuglsang L (2001) Three perspectives in STS in the policy context. In: Cutcliffe SH, Mitcham C (eds) Visions of STS: Counterpoints in science, technology, and society studies state university of New York Press. Albany, NY, pp 35-49
36. Godin B (2006) The linear model of innovation: The historical construction of an analytical framework. Sci Technol Human Values 31(6):639-667. https://doi.org/ $10.1177 / 0162243906291865$

37. Irwin A (2008) STS perspectives on scientific governance. In: Hackett EJ, Amsterdamska O, Lynch M, Wajcman J (eds) The handbook of science and technology studies, third edition. The MIT Press, Cambridge, MA and London,

38. Schot J, Rip A (1997) The past and future of constructive technology assessment. Technol Forecast Soc Chang 54(2):251-268. https://doi.org/10.1016/S0040-1625(96) 00180-1

39. te Kulve H, Rip A (2011) Constructing productive engagement: Pre-engagement tools for emerging technologies. Sci Eng Ethics 17(4):699-714. https://doi. org/10.1007/s11948-011-9304-0

40. Rip A, Kulve Ht (2008) Constructive technology assessment and socio-technical scenarios. In: Fisher E, Selin C, Wetmore JM (eds) The yearbook of nanotechnology in society, volume I: Presenting futures. Springer Netherlands, Dordrecht, pp 49-70. https://doi. org/10.1007/978-1-4020-8416-4_4

41. Borup M, Brown N, Konrad K, Van Lente H (2006) The sociology of expectations in science and technology. Technology Analysis \& Strategic Management 18(34):285-298. https://doi.org/10.1080/09537320600777002

42. van Lente H, Rip A (1998) The rise of membrane technology: From rhetorics to social reality. Soc Stud Sci 28(2):221-254. https://doi.org/10.1177/030631298028002002

43. van Lente H, Rip A (1998) Expectations in Technological developments: An example of prospective structures to be filled in by agency. In: Disco C, van der Meulen B (eds) Getting new technologies together: Studies in making sociotechnical order. Walter de Gruyter, Berlin, New York, pp 203-230

44. van Lente H (1993) Promising technology. The Dynamics of Expectations in Technological Developments. University of Twente, Enschede

45. Grin J, Grunwald A (2000) Vision assessment: Shaping technology in 21 st century society. Towards a Repertoire for Technology Assessment. Springer, Berlin and Heidelberg

46. Coenen C, Simakova E (2013) Introduction. STS policy interactions, technology assessment and the governance of technovisionary sciences. Science, Technology \& Innovation Studies (STI). 9(2):3-20

47. Konrad KE, van Lente H, Groves C, Selin C (2016) Performing and governing the future in science and technology. In: Felt U, Fouche R, Miller CA, SmithDoerrv L (eds) The handbook of science and technology studies, vol 3. MIT Press. Cambridge, MA, pp 465-493

48. Bryant R, Knight DM (2019) The anthropology of the future. Cambridge University Press, Cambridge

49. Zwart H, Nelis A (2009) What is ELSA genomics? EMBO Rep 10(6):540-544. https://doi.org/10.1038/ embor.2009.115

50. Tran TA, Daim T (2008) A taxonomic review of methods and tools applied in technology assessment. Technol 
Forecast Soc Chang 75(9):1396-1405. https://doi.org/10. 1016/j.techfore.2008.04.004

51. Bechtold U, Fuchs D, Gudowsky N (2017) Imagining socio-technical futures - challenges and opportunities for technology assessment. J Responsible Innov 4(2):85-99. https://doi.org/10.1080/23299460.2017.1364617

52. Rip A (2006) Folk theories of nanotechnologists. Science as Culture 15(4):349-365. https://doi.org/10.1080/ 09505430601022676

53. Kuhlmann S, Stegmaier P, Konrad K (2019) The tentative governance of emerging science and technology-a conceptual introduction. Res Policy 48(5):1091-1097. https://doi.org/10.1016/j.respol.2019.01.006

54. Grunwald A (2011) Responsible innovation: Bringing together technology assessment, applied ethics, and STS research. Enterprise and Work Innovation Studies 7:9-31

55. Genus A, Stirling A (2018) Collingridge and the dilemma of control: Towards responsible and accountable innovation. Res Policy 47(1):61-69. https://doi.org/ 10.1016/j.respol.2017.09.012

56. Brown N, Rappert B, Webster A (2000) Contested futures: A sociology of prospective techno-science. Ashgate, Burlington, VT

57. Jasanoff S, Kim S-H (2015) Dreamscapes of modernity: Sociotechnical imaginaries and the fabrication of power. University of Chicago Press, Chicago

58. Grunwald A (2019) The objects of technology assessment. Hermeneutic extension of consequentialist reasoning. J Responsible Innov. 1-17. https://doi.org/10.1080/ 23299460.2019.1647086

59. Swierstra T, te Molder H (2012) Risk and soft impacts. In: Roeser S, Hillerbrand R, Sandin P, Peterson M (eds) Handbook of risk theory: Epistemology, decision theory, ethics, and social implications of risk. Springer, Dordrecht, pp 1049-1066. https://doi.org/10.1007/97894-007-1433-5_42

60. von Schomberg R (2014) The quest for the 'right' impacts of science and technology: A framework for responsible research and innovation. In: van den Hoven J, Doorn N, Swierstra T, Koops B-J, Romijn H (eds) Responsible innovation 1: Innovative solutions for global issues. Springer, Dordrecht, pp 33-50. https://doi. org/10.1007/978-94-017-8956-1_3

61. Foley RW, Guston DH, Sarewitz D (2018) Towards the anticipatory governance of geoengineering. In: Blackstock JJ, Low S (eds) Geoengineering our climate? Ethics, politics, and governance. Routledge, London

62. Dupuy J-P, Grinbaum A (2004) Living with uncertainty: Toward the ongoing normative assessment of nanotechnology. Techné: Research in Philosophy and Technology 8 (2):4-25

63. Jasanoff S (2016) The ethics of invention: Technology and the human future. W. W. Norton \& Company, New York and London

64. Poli R (2019) Working with the future: Ideas and tools to govern uncertainty. Bocconi University Press, Milano

65. Miller R (2018) Transforming the future: Anticipation in the 21 st century. Routledge, London

66. Glenn JC, Gordon TJ (2009) Futures research methodology - Version 3.0. The Millennium Project,
67. Miller R (2015) Learning, the future, and complexity. An essay on the emergence of futures literacy. Eur J Educ. 50(4):513-523. https://doi.org/10.1111/ejed.12157

68. Jasanoff S (2003) Technologies of humility: Citizen participation in governing science. Minerva 41(3):223-244. https://doi.org/10.1023/a:1025557512320

69. Sarewitz DR, Pielke RA, Byerly R (2000) Prediction: Science, decision making, and the future of nature. Island Press, Washington, D.C.

70. Dupuy J-P (2007) Complexity and uncertainty: A prudential approach to nanotechnology. In: Allhoff F, Lin P, Moor JH, Weckert J, Roco MC (eds) Nanoethics. The ethical and social implications of nanotechnology. Hoboken, NJ, John Wiley \& Sons, pp 119-132

71. Feenberg A (2002) Transforming technology. Oxford University Press, Oxford

72. Callon M (2007) What does it mean to say that economics is performative? In: MacKenzie D, Muniesa F, Siu L (eds) Do economists make markets? Princeton University Press, Princeton, NJ, pp 311-357

73. Voß J-P, Freeman R (2016) Introduction: Knowing governance. In: Voß J-P, Freeman R (eds) Knowing governance (Palgrave studies in science, knowledge and policy). Palgrave Macmillan, London, pp 1-33

74. Kleine A (1996) The age of heretics: A history of radical thinkers who reinvented corporate management. Nicholas Brealey, London

75. Wack P (1985) Scenarios: Uncharted waters ahead. Harvard Business Review 63(5):72-89. https://hbr.org/1985/ 09/scenarios-uncharted-waters-ahead

76. Cornelius P, Van de Putte A, Romani M (2005) Three decades of scenario planning in Shell. California Management Review 48(1):92-109

77. Rohrbeck R, Gemunden HG Making your R\&D future proof: The roles of corporate foresight in innovation management. In: PICMET'09-2009 Portland international conference on management of engineering \& technology, Portland, OR, 2009. IEEE, pp 835-842. https://doi. org/10.1109/PICMET.2009.5262043

78. Commission E (2020) 2020 Strategic foresight report - charting the course towards a more resilient Europe. European Commission, Brussels

79. Brey PAE (2017) Ethics of emerging technologies. In: Hansson SO (ed) The ethics of technology: Methods and approaches. Bowman \& Littlefield, London \& New York, pp 175-192

80. New Zealand Ministry of Research S, and Technology (2006) nanoscience + nanotechnologies. Ministry of Research, Science, and Technology, Wellington

81. Meador MA, Files B, Li J, Manohara H, Powell D, Siochi EJ (2010) DRAFT Nanotechnology Roadmap Technology Area 10. National Aeronautics and Space Administration (NASA).

82. Arnaldi S (2018) Retooling techno-moral scenarios. A revisited technique for exploring alternative regimes of responsibility for human enhancement. Nano Ethics. 12(3):283-300. https://doi.org/10.1007/ s11569-018-0329-6 
83. van der Burg S (2009) Imagining the future of photoacoustic mammography. Sci Eng Ethics 15(1):97-110. https://doi.org/10.1007/s11948-008-9079-0

84. Johnson KA, Dana G, Jordan NR, Draeger KJ, Kapuscinski A, Schmitt Olabisi LK, Reich PB (2012) Using participatory scenarios to stimulate social learning for collaborative sustainable development. Ecology and Society 17 (2). https://doi.org/10.5751/ES-04780-170209

85. Betten AW, Rerimassie V, Broerse JEW, Stemerding D, Kupper F (2018) Constructing future scenarios as a tool to foster responsible research and innovation among future synthetic biologists. Life Sciences, Society and Policy 14(1):21. https://doi.org/10.1186/ s40504-018-0082-1

86. Schartinger D, Wilhelmer D, Holste D, Kubeczko K (2012) Assessing immediate learning impacts of large foresight processes. Foresight 14(1):41-55. https://doi. org/10.1108/14636681211210350

87. Flyvbjerg B (2001) Making social science matter: Why social inquiry fails and how it can succeed again. Cambridge University Press, Cambridge

88. Granjou C, Walker J, Salazar JF (2017) The politics of anticipation: On knowing and governing environmental futures. Futures 92:5-11. https://doi.org/10.1016/j. futures.2017.05.007

89. Vervoort JM, Bendor R, Kelliher A, Strik O, Helfgott AER (2015) Scenarios and the art of worldmaking. Futures 74:62-70. https://doi.org/10.1016/j.futures.2015.08.009

90. Grunwald A (2013) Modes of orientation provided by futures studies: Making sense of diversity and divergence. European Journal of Futures Research 2(1):30. https://doi.org/10.1007/s40309-013-0030-5

91. Selin C (2011) Negotiating plausibility: Intervening in the future of nanotechnology. Sci Eng Ethics 17(4):723737. https://doi.org/10.1007/s11948-011-9315-x

92. Robinson DKR (2009) Co-evolutionary scenarios: An application to prospecting futures of the responsible development of nanotechnology. Technol Forecast Soc Chang 76(9):1222-1239. https://doi.org/10.1016/j. techfore.2009.07.015

93. Lehoux P, Miller FA, Williams-Jones B (2020) Anticipatory governance and moral imagination: Methodological insights from a scenario-based public deliberation study. Technol Forecast Soc Chang 151:119800. https://doi.org/ 10.1016/j.techfore.2019.119800

94. Konrad K, Böhle K (2019) Socio-technical futures and the governance of innovation processes - an introduction to the special issue. Futures 109:101-107. https://doi.org/ 10.1016/j.futures.2019.03.003

95. Ahlqvist T, Rhisiart M (2015) Emerging pathways for critical futures research: Changing contexts and impacts of social theory. Futures 71:91-104. https://doi.org/10. 1016/j.futures.2015.07.012

96. Inayatullah S (1990) Deconstructing and reconstructing the future: Predictive, cultural and critical epistemologies. Futures 22(2):115-141. https://doi.org/10.1016/ 0016-3287(90)90077-U

97. Slaughter RA (1998) Futures studies as an intellectual and applied discipline. Am Behav Sci 42(3):372-385. https://doi. org/10.1177/0002764298042003008
98. Slaughter RA (2003) Futures beyond dystopia: Creating social foresight. Routlege, London and New York

99. Grunwald A vision assessment as a new element of the technology futures analysis toolbox. In: Scapolo F, Cahill E (eds) New horizons and challenges for future-oriented technology analysis. Proceedings of the EU-US Scientific Seminar. New Technology Foresight, Forecasting \& Assessment Methods, JRC-IPTS, Seville (Spain), May 13-14, 2004.

100. Grunwald A (2014) The hermeneutic side of responsible research and innovation. Journal of Responsible Innovation 1(3):274-291. https://doi.org/10.1080/23299460. 2014.968437

101. Decker M, Grin J, Grunwald A, Mambrey P, Reuzel R, Tepper A, van der Wilt GJ (2000) Outline. In: Grin J, Grunwald A (eds) Vision assessment: Shaping technology in 21st century society. Towards a repertoire for technology assessment. Springer, Berlin and Heidelberg, pp 1-6

102. Selin C (2007) Expectations and the emergence of nanotechnology. Sci Technol Human Values 32(2):196-220. https://doi.org/10.1177/0162243906296918

103. Lösch A (2006) Anticipating the futures of nanotechnology: Visionary images as means of communication. Technology Analysis \& Strategic Management 18(3-4):393-409. https:// doi.org/10.1080/09537320600777168

104. Schneider C, Lösch A (2019) Visions in assemblages: Future-making and governance in FabLabs. Futures 109:203-212. https://doi.org/10.1016/j.futures.2018.08. 00

105. Rip A (2018) Futures of science and technology in society. Springer VS, Wiesbaden

106. Grunwald A (2017) Assigning meaning to NEST by technology futures: Extended responsibility of technology assessment in RRI. Journal of Responsible Innovation 4(2):100-117. https://doi.org/10.1080/23299460. 2017.1360719

107. Konrad KE, Alvial Palavicino C (2017) Evolving patterns of governance of, and by, Expectations: The graphene hype wave. In: Bowman DM, Stokes E, Rip A (eds) Embedding new technologies into society: A regulatory, ethical and societal perspective. Pan Standford Pub, Singapore, pp 187-217

108. Inayatullah S (1998) Causal layered analysis: Poststructuralism as method. Futures 30(8):815-829. https://doi. org/10.1016/S0016-3287(98)00086-X

109. Lucivero F (2016) Promises, expectations and visions: On appraising the plausibility of socio-technical futures. In: Ethical assessments of emerging technologies: Appraising the moral plausibility of technological visions. Springer International Publishing, Cham, pp 37-61. https://doi.org/10.1007/978-3-319-23282-9_2

110. Grunwald A (2018) The spreading of techno-visionary futures. In: Bunde A, Caro J, Kärger J, Vogl G (eds) Diffusive spreading in nature, technology and society. Springer, Cham, pp 295-309. https://doi.org/10.1007/ 978-3-319-67798-9_15

111. Coenen C (2014) Transhumanism and its genesis: The shaping of human enhancement discourse by visions of the future. HUMANAMENTE J Philos Stud 7(26):35-58 
112. Arnaldi S (2008) Framing pragmatic validity: Theoretical reorientations of the regio futures. In: Gasior-Niemiec A, Kukliński A, Lamentowicz W (eds) Faces of the 21st century. Oficyna Wydawnicza Rewasz, Poland, pp 108-121

113. Fuller S (2018) In praise of precipitatory governance as a (meta-)principle of responsible innovation. RT J Res Policy Eval. 6(1)

114. Nordmann A, Rip A (2009) Mind the gap revisited. Nat Nanotechnol 4(5):273-274. https://doi.org/10.1038/ nnano. 2009.26

115. Lucivero F, Swierstra T, Boenink M (2011) Assessing expectations: Towards a toolbox for an ethics of emerging technologies. NanoEthics 5(2):129-141. https://doi. org/10.1007/s11569-011-0119-x

116. Urueña S (2019) Understanding "plausibility": A relational approach to the anticipatory heuristics of future scenarios. Futures 111:15-25. https://doi.org/10.1016/j. futures.2019.05.002

117. Grunwald A (2010) From speculative nanoethics to explorative philosophy of nanotechnology. NanoEthics 4(2):91-101. https://doi.org/10.1007/ s11569-010-0088-5

118. York R, Clark B (2007) The problem with prediction: Contingency, emergence, and the reification of projections. Sociol Q 48(4):713-743

119. Selin C, Guimaraes Pereira Â (2013) Pursuing plausibility. Int J Foresight Innov Policy. 9 (2/3/4):93-109. https://doi.org/10.1504/ijfip.2013.058616

120. Sarewitz D (2011) Anticipatory governance of emerging technologies. In: Marchant GE, Allenby BR, Herkert JR (eds) The growing gap between emerging technologies and legal-ethical oversight: The pacing problem. Springer Netherlands, Dordrecht, pp 95-105. https://doi.org/10.1007/978-94-007-1356-7_7

121. Racine E, Martin Rubio T, Chandler J, Forlini C, Lucke J (2014) The value and pitfalls of speculation about science and technology in bioethics: The case of cognitive enhancement. Med Health Care Philos 17(3):325-337. https://doi.org/10.1007/s11019-013-9539-4

122. Sarpong D, Eyres E, Batsakis G (2019) Narrating the future: A distentive capability approach to strategic foresight. Technol Forecast Soc Chang 140:105-114. https:// doi.org/10.1016/j.techfore.2018.06.034

123. Cunha MPE (2004) Time traveling: Organizational foresight as temporal reflexivity. In: Tsoukas H, Shepherd J (eds) Managing the future: Foresight in the knowledge economy. Blackwell Publishing, Oxford, pp 133-149

124. Amsler S, Facer K (2017) Introduction to 'learning the future otherwise: Emerging approaches to critical anticipation in education.' Futures 94:1-5. https://doi.org/10. 1016/j.futures.2017.09.004

125. Sardar Z (2010) The namesake: Futures; futures studies; futurology; futuristic; foresight-what's in a name? Futures 42(3):177-184. https://doi.org/10.1016/j.futures. 2009.11.001
126. van der Duin P (2018) Toward "responsible foresight": Developing futures that enable matching future technologies with societal demands. World Futures Review 11(1):69-79. https://doi.org/10.1177/ 1946756718803721

127. Mittelstadt BD, Stahl BC, Fairweather NB (2015) How to shape a better future? Epistemic difficulties for ethical assessment and anticipatory governance of emerging technologies. Ethical Theory Moral Pract 18(5):1027-1047. https://doi.org/10.1007/ s 10677-015-9582-8

128. Moniz AB (2006) Scenario-building methods as a tool for policy analysis. In: Rihoux B, Grimm H (eds) Innovative comparative methods for policy analysis: Beyond the quantitative-qualitative divide. Springer, Boston, MA, pp 185-209. https://doi.org/10.1007/0-387-28829-5_9

129. Ruggiu D (2019) Models of anticipation within the responsible research and innovation framework: The two RRI approaches and the challenge of human rights. NanoEthics 13(1):53-78. https://doi.org/10.1007/ s11569-019-00337-4

130. Ruggiu D (2018) Implementing a responsible, research and innovation framework for human enhancement according to human rights: The right to bodily integrity and the rise of 'enhanced societies.' Law Innov Technol 10(1):82-121. https://doi.org/10.1080/17579961.2018. 1452177

131. Fricker M (2007) Epistemic injustice: Power and the ethics of knowing. Oxford University Press, New York, NY

132. Linker M (2014) Epistemic privilege and expertise in the context of meta-debate. Argumentation 28(1):67-84. https:// doi.org/10.1007/s10503-013-9299-6

133. Bondy P (2010) Argumentative injustice Informal Logic 30(3):263-278

134. Valkenburg G, Mamidipudi A, Pandey P, Bijker WE (2019) Responsible innovation as empowering ways of knowing. J Res Innov 7(1):6-25. https://doi.org/10.1080/ 23299460.2019.1647087

135. Schmidt-Scheele R (2020) 'Plausible' energy scenarios?! How users of scenarios assess uncertain futures. Energy Strategy Rev. 100571. https://doi.org/10.1016/j.esr.2020. 100571

136. Urueña S, Rodríguez H, Ibarra A (2021) Foresight and responsible innovation: Openness and closure in anticipatory heuristics. Futures 134, 102852

137. Fischer N, Dannenberg S (2021) The social construction of futures. Futures 129, 102729

Publisher's Note Springer Nature remains neutral with regard to jurisdictional claims in published maps and institutional affiliations. 